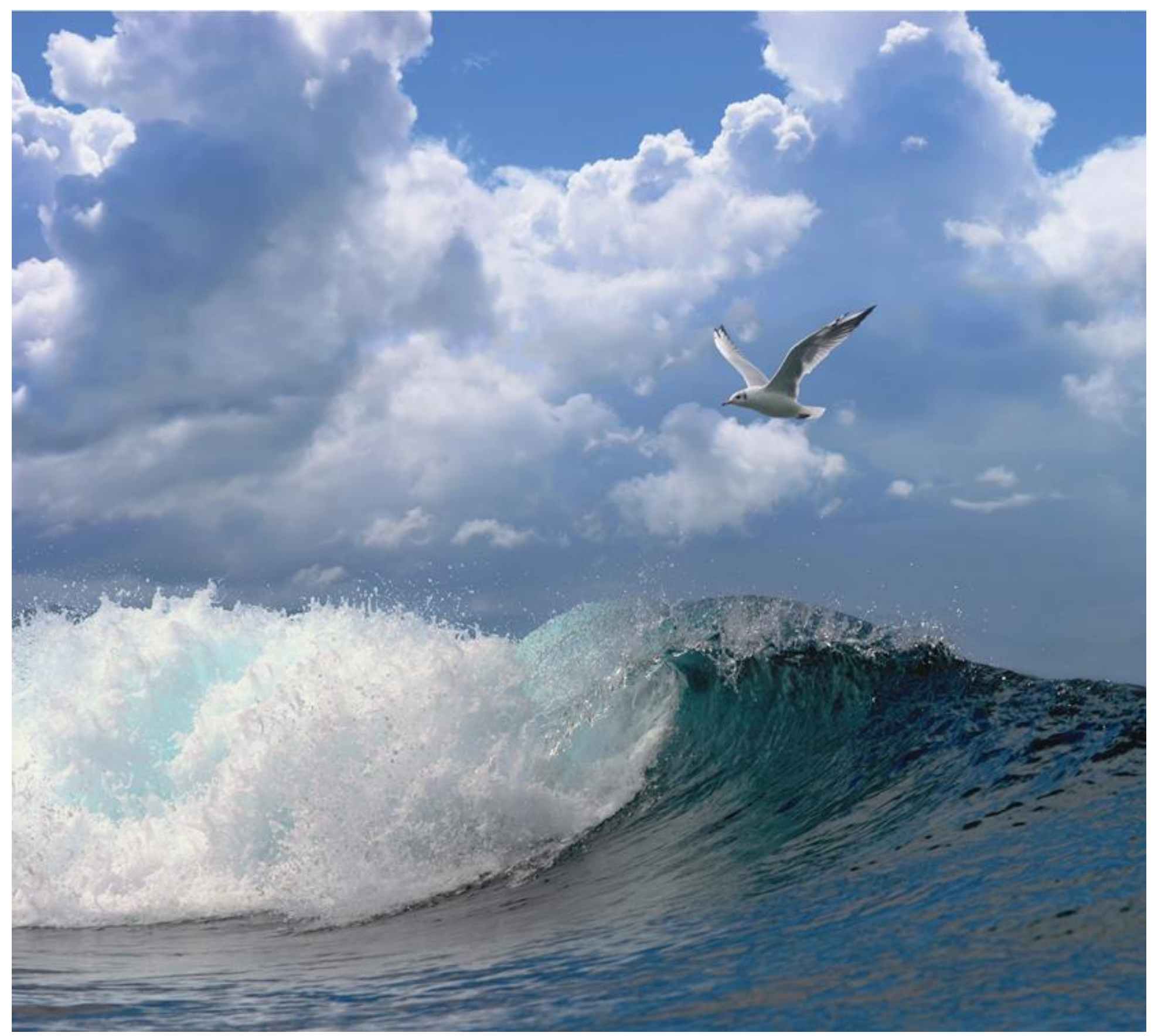

Field strength profile in and above the seabed as reference to pulse trawl fishing on Dover sole (Solea solea) 


\section{Field strength profile in and above the seabed as reference to pulse trawl fishing on Dover sole (Solea solea)}

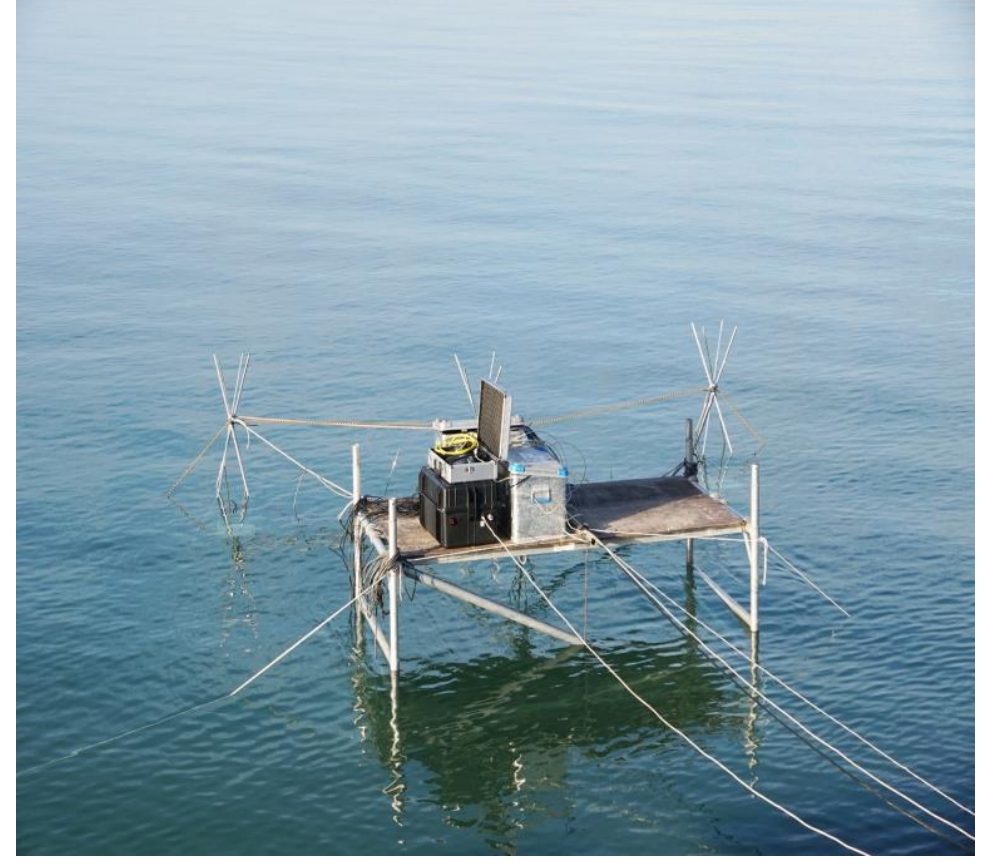


Dick de Haan \& Dirk Burggraaf, 2018. Field strength profile in and above the seabed as reference to pulse trawl fishing on Dover sole (Solea Solea). Wageningen, Wageningen Marine Research (University \& Research centre), Wageningen Marine Research report C022/18. 33 pp.

Keywords: pulse trawl, sole, field strength, sediment.

Client: $\quad$ Ministry of Agriculture, Nature and Food Quality

Attn.: Ir. H. Snijders

Postbus 20401

2500 EK Den Haag

BAS code BO-43-023.02-003

This report can be downloaded for free from https://doi.org/10.18174/445481

Wageningen Marine Research provides no printed copies of reports

Wageningen Marine Research is ISO 9001:2008 certified.

Photo cover: Dick de Haan

(C) 2016 Wageningen Marine Research Wageningen UR

Wageningen Marine Research The Management of Wageningen Marine Research is not responsible for resulting institute of Stichting Wageningen damage, as well as for damage resulting from the application of results or Research is registered in the Dutch research obtained by Wageningen Marine Research, its clients or any claims traderecord nr. 09098104, BTW nr. NL 806511618 related to the application of information found within its research. This report has been made on the request of the client and is wholly the client's property. This report may not be reproduced and/or published partially or in its entirety without the express written consent of the client. 


\section{Contents}

$\begin{array}{lr}\text { Summary } & 4\end{array}$

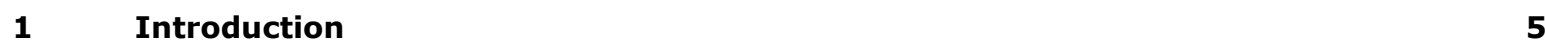

$2 \quad$ Materials and methods $\quad 7$

$\begin{array}{lll}2.1 & \text { Measurement principle for sediment application } & 7\end{array}$

2.1.1 Field strength references $\quad 8$

2.2 Probe design and positioning $\quad 8$

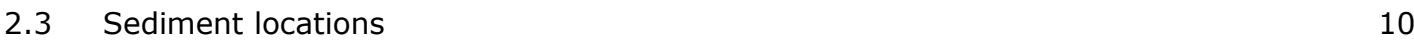

2.4 Pulse equipment $\quad 11$

2.4.1 Electrode arrangement $\quad 11$

2.4.2 Pulse settings \& control $\quad 11$

2.5 Measurement equipment 12

2.6 Analysis procedure $\quad 12$

$3 \quad$ Results $\quad 13$

3.1 Field strength assessment \& justification 14

3.2 Results on a compact sandy layer (Neeltje Jans) 16

3.3 Results on a mixture of sand and mud (Mokbaai) 16

$\begin{array}{lll}3.4 & \text { Summarised Results } & 17\end{array}$

$\begin{array}{llr}3.5 & \text { Results of both sediment conditions } & 18\end{array}$

4 Conclusions $\quad 26$

$\begin{array}{llr}5 & \text { Discussion } & 27\end{array}$

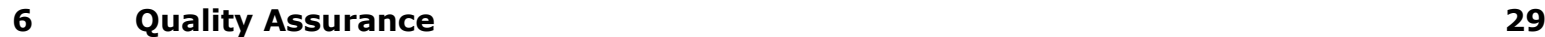

$\begin{array}{lr}\text { References } & \mathbf{3 0}\end{array}$

$\begin{array}{lr}\text { Justification } & \mathbf{3 1}\end{array}$ 


\section{Summary}

An automated measurement system was designed to sample field strength in and above the seabed at multiple positions around a conductor of a sole pulse system for a range of conductor. The experiments were conducted in the winter of 2016/2017 on two Dutch inshore locations, the Neeltje Jans rescue harbour at the sea side of the Oosterschelde barrier dam (1) and the Mokbaai shore south of the island Texel (2). The first location represents a sediment of compact North Sea sand, the second a mixture of mud and sand. Both locations have an open connection to the North Sea.

The methods involved three pairs of Delmeco conductors spread out over an area of $4.5 \times 1 \mathrm{~m}$ all connected in parallel to a single Delmeco pulse module system, applied in sole pulse gear. The conductor distance was set to $325 \mathrm{~mm}$, similar to the distance applied in earlier WMR laboratory studies, but shorter than the commercially applied distance $(420 \mathrm{~mm})$.

Field strength was sampled in a 3D coordinate system with the center of the conductor defined as $X=0, Y=0, Z=+12.5$ and the seabed surface $Z=0$.

A single experiment involved:

- Five vertical levels $(Z)$, in the water volume $(+200,+100 \mathrm{~mm})$, at the seabed $(0)$ and in the sediment $(-100,-200 \mathrm{~mm})$.

- Five positions alongside the electrode $(Y)$ ranging from $Y=+90$ to $-90 \mathrm{~mm}$ (alongside the full conductor length of $180 \mathrm{~mm}$ ) or a shifted range from $Y=0$ to $-180 \mathrm{~mm}$, covering an isolated section.

- Two positions perpendicular to the conductor center $(X)$, in close range of the conductor $(X=57.5 \mathrm{~mm})$ and at equal distance of the conductors $(X=162.5 \mathrm{~mm})$.

On both locations field strength almost evenly distributed in the water volume and sediment. At equal distance of a pair of conductors field strength in the sediment was higher in the sediment, even on the $0.3 \mathrm{~m}$ compact sandy layer on top of solid asphalt. Peaks were not always found opposite the center of the conductor, but also aside of the center and on the vertical axis indicating irregular conductivity patterns at the tested levels of $Y$ and $Z$. Variations were lower on the location with a compact sandy layer.

Field strength was linear proportional to the tested conductor voltage range of 40 to $60 \mathrm{~V}$ for all $3 \mathrm{D}$ positions with the slope of the regression declining towards the boundaries of the vertical range of $Z$. Some $60 \mathrm{~V}$ results overloaded the analogue input, these values were retrieved using the linear regression, which was a neat fit in most cases.

The highest field strength ( 220 to $263 \mathrm{~V} \cdot \mathrm{m}^{-1}$ ) was measured at seabed level $(Z=0)$ in the closest range from the conductor $(X=57.5, Y=+45 / 0 /-45, Z=0)$. The lowest measured range $\left(11\right.$ and $\left.14 \mathrm{~V} \cdot \mathrm{m}^{-1}\right)$ was found opposite the isolator $(X=57.5 \mathrm{~mm}, Y=-180 \mathrm{~mm})$ at the boundaries of the measured $Z$ axis range $(Z=+/-200)$.

At equal distance from the conductors $(X=162.5)$ field strength ranged from $36 \mathrm{~V} \cdot \mathrm{m}^{-1}(Z=-200 \mathrm{~mm})$ and $31 \mathrm{~V} \cdot \mathrm{m}^{-1}(Z=+200 \mathrm{~mm})$ measured on the compact sandy compact layer. When narrowing the $Z$ range to $+/-100 \mathrm{~mm}$ at mid-range $(X=162.5 \mathrm{~mm})$ the maximum field strength in the water volume was $7 \%$ higher than in the sediment. These values slightly reduced on the location with lower water conductivity (Mokbaai). When the observed vertical range is narrowed to $+/-100 \mathrm{~mm}$, field strength in close range did not reduce towards the position at equal distance.

Replicate field strength measurements in the compact sandy sediment (Neeltje Jans) showed low variation and were all within 2-6 V.m-1. On the less compact sediment of sand and mud (Mokbaai), measurements varied between replicates and also varied significantly between conductor pairs of a single experiment. The in-situ measurements corroborate the field strength measurements of de Haan et al (2016) carried out in tanks and show that the soft sediments of the typical fishing grounds of the sole fishery does not reduce the electric field.

This research was performed within the programme Policy Support('Beleidsondersteunend Onderzoek', BO) of the Ministry of Agriculture, Nature and Food Quality. 


\section{Introduction}

To assess the consequences of the transition of beam to pulse trawling on the ecosystem research was executed to study the effects on the ecosystem, bycatch and benthos and sustainable exploitation. The beam trawl enabled a fixed horizontal net opening and an array of tickler chains to deter sole out of the sediment into the net. The increase of the number of tickler chains and towing speed resulted in a higher catch efficiency (Daan, 1997, Rijnsdorp et al., 2008). So far the transition to pulse trawl fishing did not show to have negative effects, apart from some species, like gadoids of marketable size, may become injured on passing the electrified parts in close range. When observed from the technical perspective the transition may have many operational advantages, like reduction of engine propulsion power by $50 \%$ (and likewise a reduction of $\mathrm{CO}^{2}$ exhaust) and the reduction of bycatch of benthos (38\%) and undersized fish (56\%) (van Marlen et al. 2014). Pulse trawls operate at an average power of $0.7 \mathrm{~kW}$ per meter beam length. The electric field is heterogeneous with highest field strength occurring close to the conductors (de Haan et al., 2016).

At management level solid directives are required, which are manageable by control \& enforcement. An important management question is if the electric seabed intrusion compares to the mechanical stimulus. Traditional beam trawls cause a flattening of the bottom profile and damage bioturbation mounds (Fonteyne, 2000 and Kaiser \& Spencer, 1996) and several studies provided evidence on the short-term impact of beam trawls on benthic species (Bergman \& Hup, 1992, Bergman and Van Santbrink, 2000, Kaiser \& Spencer, 1996, Lindeboom \& de Groot, 1998). Depestele et al. (2015) report greater alteration of the bathymetry of a conventional beam trawl against a pulse trawl and that this is likely to be a result of greater penetration. So to conclude the penetration of tickler chain trawls is difficult to predict and will vary with the type of sediment. Beam trawls may exclude itself by its own weight to operate on muddy type of sediments, while the lighter pulse trawls may have opportunities and extend to these environments. Eigaard et al., (2016) and Rijnsdorp et al., (2016) categorised the seabed pressure, categorised a range of trawls and defined trawl footprints and ecosystem pressure indicators. The footprint of a pulse trawl is the present challenge to design. Rather than traditional beam trawls the footprint of pulse exposure can also be studied in the laboratory. The impact of a single pulse trawl string to a range of species was simulated in a laboratory as shown in de Haan et al. (2016) and in these studies field strength was reported as reference to the effects.

In 2016, a 4-year research programme commissioned by the Dutch ministry of Economic Affairs (now: Ministry of Agriculture, Nature and Food Quality) was started with the aim to develop knowledge on the long term impact of the commercial application of pulse trawls in the North Sea. The research was organised in two PhD research fields: 1 ) the effects on marine organisms and 2) the effects on the benthic ecosystem.

Research questions in these studies are:

Marine organisms:

- what is the response of marine organisms to the exposure by a range of pulse parameters?

Benthic ecosystem

- what is the effect of pulse trawling on the functioning and biogeochemistry of benthic ecosystems (short-term and long-term effects)?

Sea bed

- what is the effect of pulse trawling on the fish stocks and the benthic ecosystem at the scale of the North Sea

The synthesis of the outcome should evoke the answers on the effects of the transition of the tickler chain beam trawl fleet to a pulse trawl fleet.

In these studies models are used to measure the impact with field strength as relevant indicator to refer to. These models require validation of the electric field strength around a pair of conductors in the water volume and in the sediment. So far existing data are based on the field strength profile in the water column (de Haan et al., 2016) and information on the sediment profile is lacking. 
In this study a first step was made to measure the electric field simultaneously in the water volume and sediment at multiple positions around a pair of conductors as common references for the management of the sole pulse trawl and to validate the models applied in laboratory of the new defined framework studies. 


\section{Materials and methods}

\subsection{Measurement principle for sediment application}

In previous WMR field strength studies the probe sensor consisted of a twisted pair of copper wires of $2.5 \mathrm{~mm}^{2}$ with the sensing bodies in opposite direction at $90^{\circ}$ angle with the pole (Figure 1). The distance between the sensing elements was $25 \mathrm{~mm}$. Analogue signal amplitudes were monitored from oscilloscope images (de Haan et al., 2016).

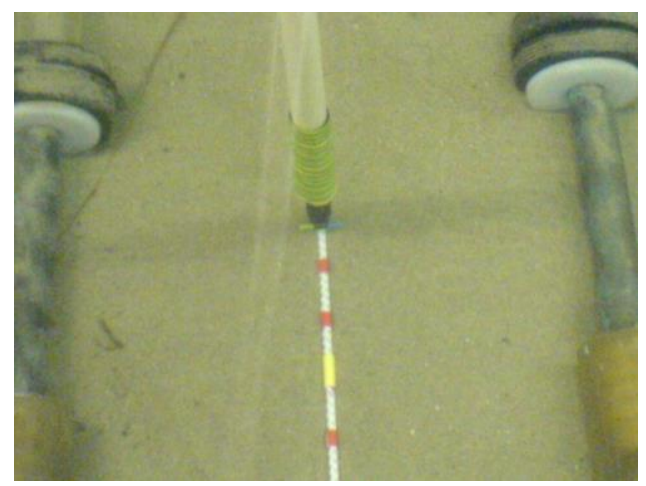

Figure 1 Single field strength probe system operated in WMR laboratory studies.

To measure field strength simultaneously at multiple positions in the water volume and sediment this concept had to be automated and the probe sensing design for sediment application had to be adjusted. The positioning of the sensor in the sediment should not affect the sediment characteristics (density and water leakage). Instead of a single pole with sensors bodies sideways, dual probes were paired at five equal vertical levels of sensor bodies, two in the water volume, one at seabed level and two in the sediment (Figure 2). A single field strength measurement is the differential voltage measured with the probes perpendicular to the conductor. Field strength $\left(\mathrm{V} \cdot \mathrm{m}^{-1}\right)$ relates to the differential voltage between opposite sensors at equal distance of the sensors $(1 / 2 d)$ according the equation:

$F=\operatorname{Vab}^{*}(1000 / d)$

where $V$ is the differential voltage between the sensors $A$ and $B$ positioned at distance $d=45 \mathrm{~mm}$ from each other. The 1000 in the above equation converts the measurement to $\mathrm{V} / \mathrm{m}^{-1}$.

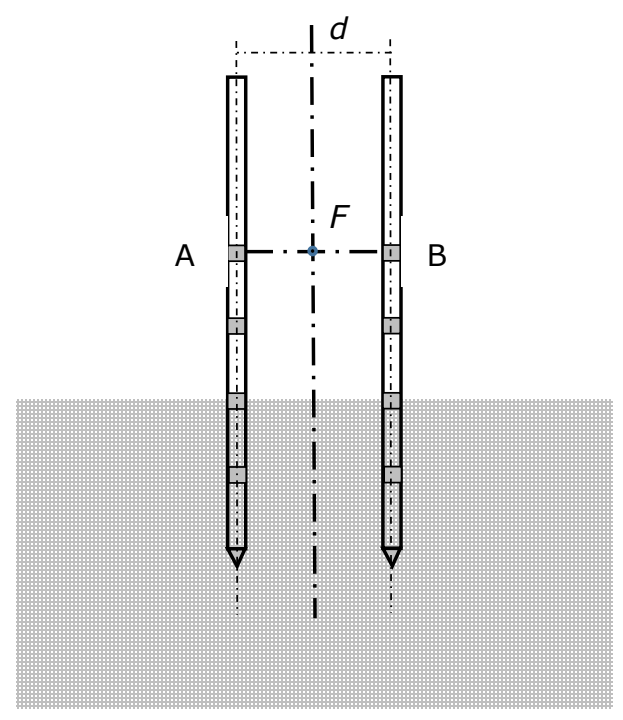

Figure 2 Single example ( 1 of 5) of a field strength measurement for a paired sensor system (A.B) with the field strength referred position $F$ at equal distance $(1 / 2 d)$ of the probes. 
The physical design aimed at the lowest intrusion of the sediment characteristics, with the diameter adapted to support internal sensor wiring and rigid enough to withstand the positioning in compact layer of sand.

A second design consideration was the minimum distance between probes against the maximum voltage input range available at the instrumentation input channel. Based on the output voltage of the $5 \mathrm{~mm}$ probe a distance unit of $45 \mathrm{~mm}$ would be an acceptable compromise of lowest intrusive effects, while the signal amplitude would be within the maximum input voltage range of $+/$ $10 \mathrm{~V}$ of the measurement system. As sediment characteristics for a given location were unknown and could vary locally three conductor pairs were used to compensate for variable conductivity conditions and to observe field strength ratings over a wider area than just a single small area and to compensate for failures or other unexpected errors.

A third design boundary was the number of input channels against the requirement to sample these numbers simultaneously with a sample rate large enough to sense the short intervals where the pulse signal occur, which is only $2 \%$ of a complete pulse cycle ( $\approx 2 \%$ duty cycle).

Given the aim to monitor 3 conductor pairs simultaneously at five vertical levels and 5 positions alongside each of the three conductor pairs (75 field strength measurements), a total number of 150 (75 $\mathrm{A}$ and $75 \mathrm{~B}$ ) inputs channels are required. Five positions alongside a conductor require 5 pairs of probes ( $\approx 10$ probes/conductor and involve 50 input signals/conductor).

\subsubsection{Field strength references}

For this experiment the outcome of earlier field strength references were used to classify the results and the impact ranges. The main knowledge of field strength around electric fields is based on laboratory studies in WMR laboratories and IMR, Austevoll laboratories Norway, the WMR laboratory in IJmuiden and the Delmeco laboratory Colijnsplaat. References for an in-situ measurement for the present set-up is limited to the measurements on the pulse gear on board TH6, which was rigged at that time with similar Delmeco pulse hardware.

\subsection{Probe design and positioning}

Probes were built of $5 \mathrm{~mm}$ epoxy glass tubes with 4 brass cylindrical sensors of $5 \mathrm{~mm}$ height and a spear-shaped sensor of $15 \mathrm{~mm}$ at the bottom end of the probe with sensors positioned in units of 100 $\mathrm{mm}$. A 3D-coordinate system $(X, Y, Z)$ was used to define the measured positions, with the $X$ axis perpendicular to the conductor, the $Y$ axis in parallel to the conductor and on the vertical axis five levels of $Z(Z=+200,+100,0,-100,-200)$. All ranges of $Z$ are referred to seabed level $(Z=0)$, which deviates $12.5 \mathrm{~mm}$ from the centre axis of the conductor ( $25 \mathrm{~mm}$ diameter). As a result the levels of $Z$ in the water volume are at shorter range from the highest field strength than levels of $Z$ in the seabed. The polarity sign indicates a sediment level $(-)$ or water level $(+)$ relative to the seabed level $(0)$. In the inner area of a pair of probes the $X, Y$ coordinates reflect the measured field strength position (Figure 4). A full arrangement of a single experiment involved three conductor pairs spread out over an area of $4.5 \times 1 \mathrm{~m}$ (Figure 3 ). 


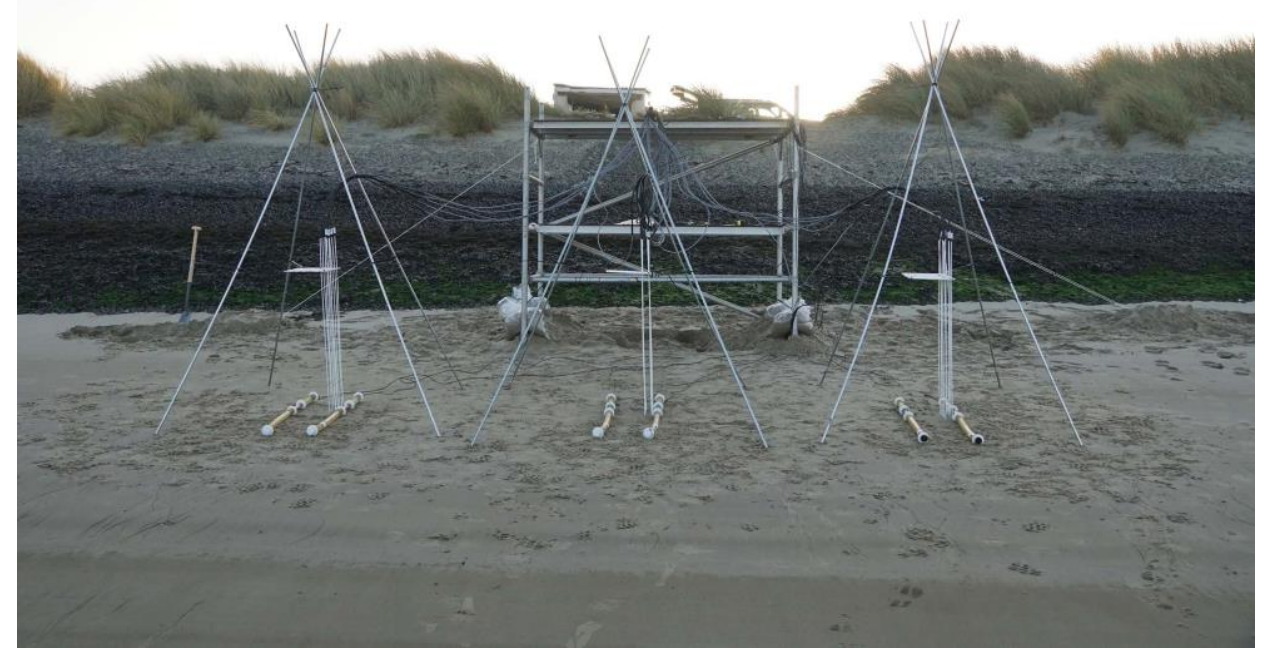

Figure 3 Preparation of a measurement trial on the borders of the Neeltje Jans harbour with three electrodes covering an area of $4.5 \times 1 \mathrm{~m}$.

Of all three conductor pairs 15 positions ( $\mathrm{X}, \mathrm{Y}$ ) were measured simultaneously. A single experiment consisted of 15 field strength positions with 30 probes wired as 15 pairs to simultaneously sample 75 field strength positions ( $X, Y$ and $Z$ ). The minimum grid unit for $X \& Y$ positions was set to $45 \mathrm{~mm}$. Given the $180 \mathrm{~mm}$ conductor length the $Y$ axis grid was lined up to the centre of the conductor $(Y=0)$ with 5 positions of $Y$ equally distributed in units of $45 \mathrm{~mm}$ (Figure 4). The probes were positioned by manual force.
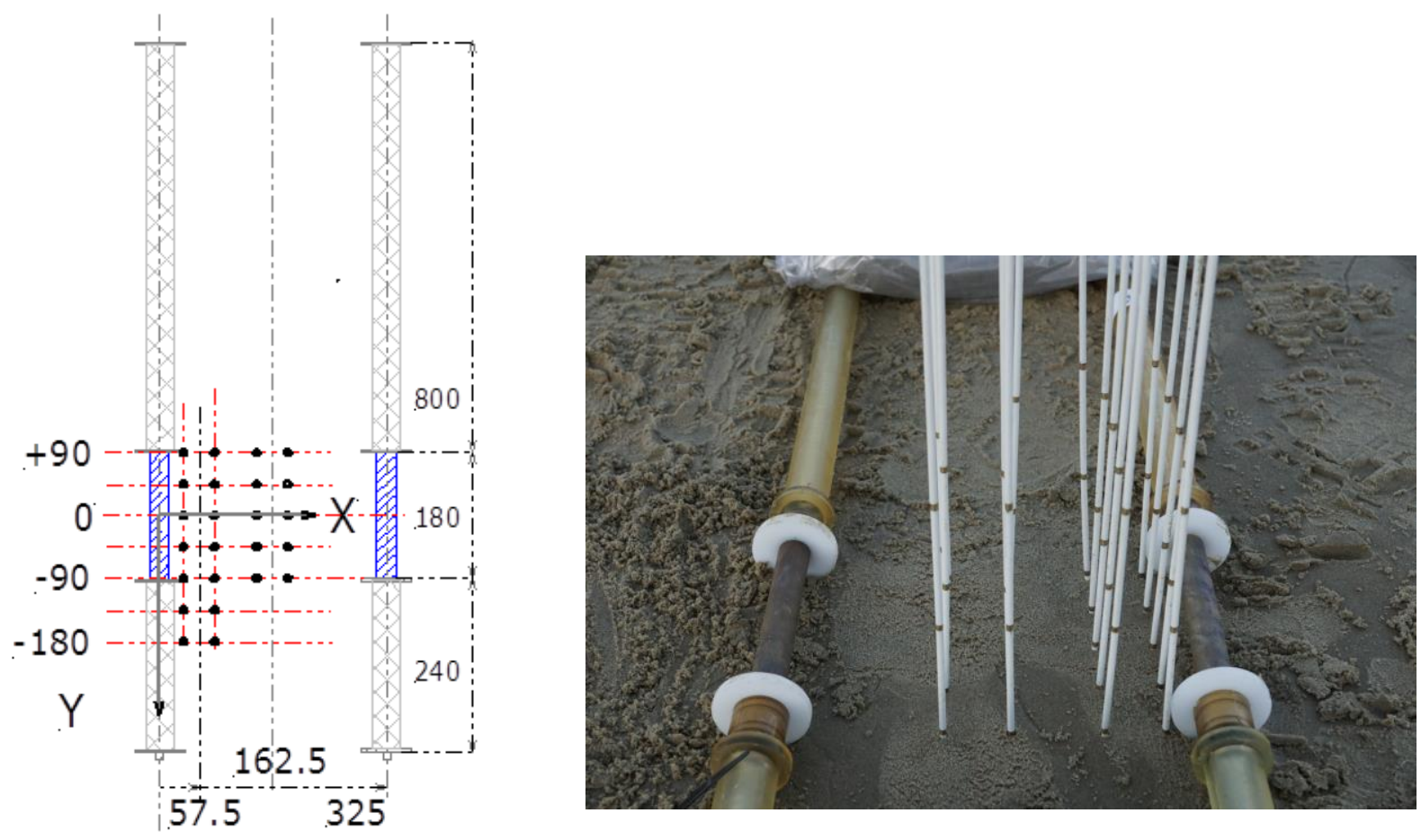

Figure 4 Probe positions in the horizontal plane between a pair of conductors (left) with the $X$ ranges 57.5 and 162.5 marking the field strength referred positions. Of all seven ranges of $Y$ five were measured in a single experiment. In addition a field trial example (right) for two positions of $X$ $(X=57.5 \& 162.5 ; Y=+90$ to -90$)$ measured in a single experiment. 
In a single case the five positions of $Y$ were centered opposite $Y=-90$ ( $Y=0$ to -180 ) to include two positions opposite the isolator $Y=-135 \&-180$ (Figure 4). On both locations two ranges of $X$ were measured, 57.5 and $162.5 \mathrm{~mm}$. The minimum distance of $X=57.5 \mathrm{~mm}(=(70 / 2)+(1 / 2 * 45)$ relates to the $70 \mathrm{~mm}$ nylon discs fixed at both ends of the conductor and the probe distance of $45 \mathrm{~mm}$. Measured ranges of $X$ were sampled either for three conductor pairs at a single range of $X(57.5 \mathrm{~mm})$, or two cases simultaneously in both ranges of X (57.5 and 162.5) for a single conductor pair (Figure $4)$. In that case the second conductor pair was used to measure the near field range $(X=57.5)$ while the third conductor pair was part of the exposure, but field strength not measured. For the positioning of probes a mould plate was used with a square grid of $45 \mathrm{~mm}$, which was also used to stabilise the probes against any impact of swell and wind (Figure 5).

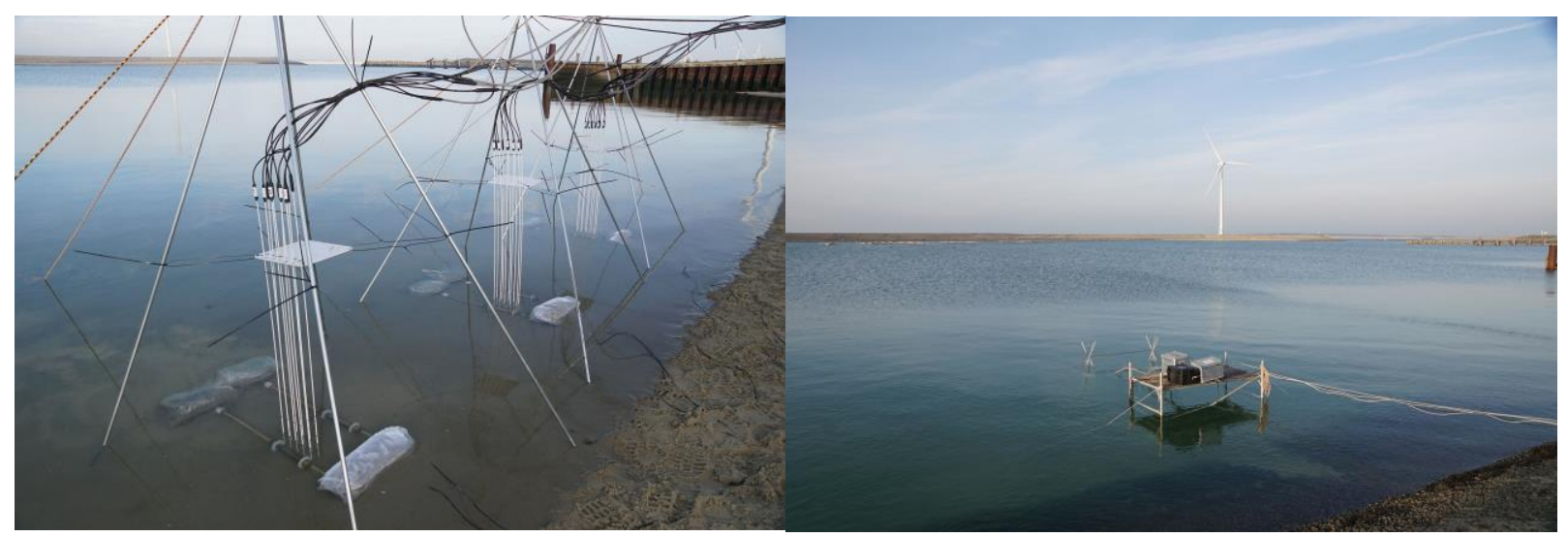

Figure 5 Measurement set-up of the experiment at the Neeltje Jans location (2016-12-14/15).

The highest field strength ratings in close range of the conductor were close to the maximum signal input range of the measuring analogue input circuits (+/-10V). To enable extrapolation for input signal overloads a lower conductor voltage was applied, ranging from 51 to $60 \mathrm{~V}$ (Neeltje Jans 2016) or 40 to $60 \mathrm{~V}$ (Mokbaai).

\subsection{Sediment locations}

The measurements were executed on two different coastal locations of different sediment types. The potential locations were selected to provide the highest salinity conditions similar to the conditions practiced during fishing further off-shore. Although locations further in-shore would provide a higher degree of shelter the salinity is likely to reduce and off-scale to the real practice of pulse fishing at sea. The first location tested in December 2016 on the border of the Neeltje Jans rescue harbour, located at the sea side of the Oosterschelde barrier dam (Figure 6).

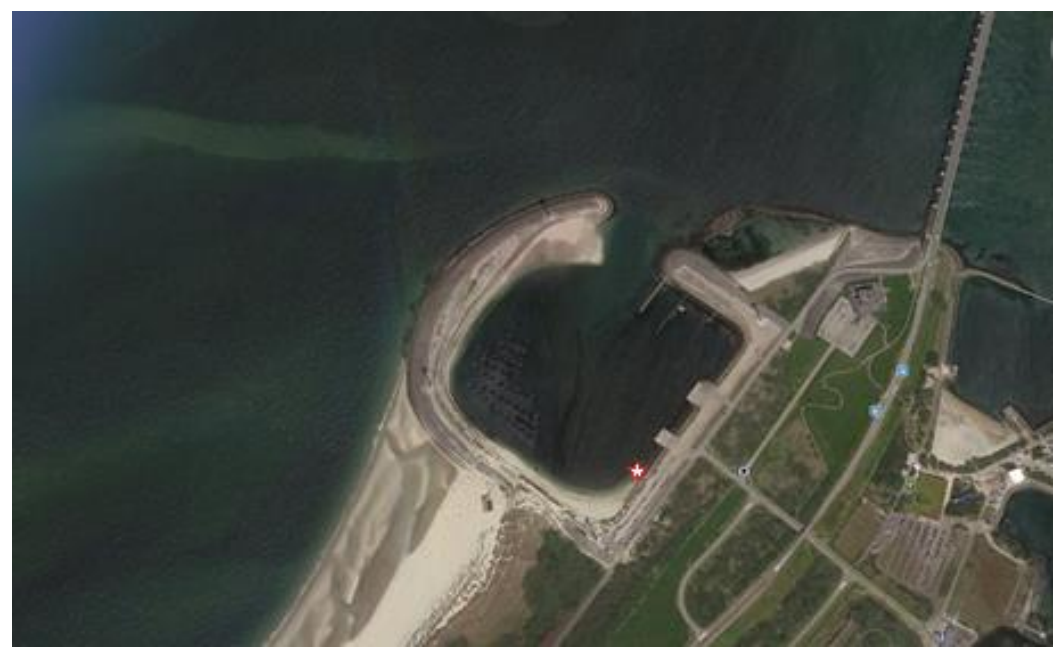

Figure 6 Location Neeltje Jans with the marked measured position. 
The borders of the Neeltje Jans outer harbour are covered with regular North Sea sand packed as a small compact layer of $0.3 \mathrm{~m}$ on top of the asphalt harbour barrier structure. The measured location did run dry at low tide and was flooded to a level of $1.9 \mathrm{~m}$ at high tide. The location provided shelter against winds from the west to south, which added to the planning of the exercise and there is an open connection with the North Sea.

The second location was on the shores of Mokbaai, which is a natural shaped bay south of the isle of Texel, of which the shores become dry at low tide and were flooded to a level of $1 \mathrm{~m}$ at high tide. Measurements were executed on the border areas at either sides of the harbour piers of the "Joost Dourlein" barracks department of the Dutch Ministry of Defence (Figure 7). The permit for this exercise was provided from the commander of the Joost Dourlein barracks and as this location is also a Natura 2000 protected area, a permit was required from the "Provinciale Staten" of Noord-Holland, division Hoorn. The median grain size distribution of the sediment in the Mokbaai was assessed in 2010 by students of the University Leeuwarden NL, division Van Hall Larenstein (pers. communication Martin Baptist).

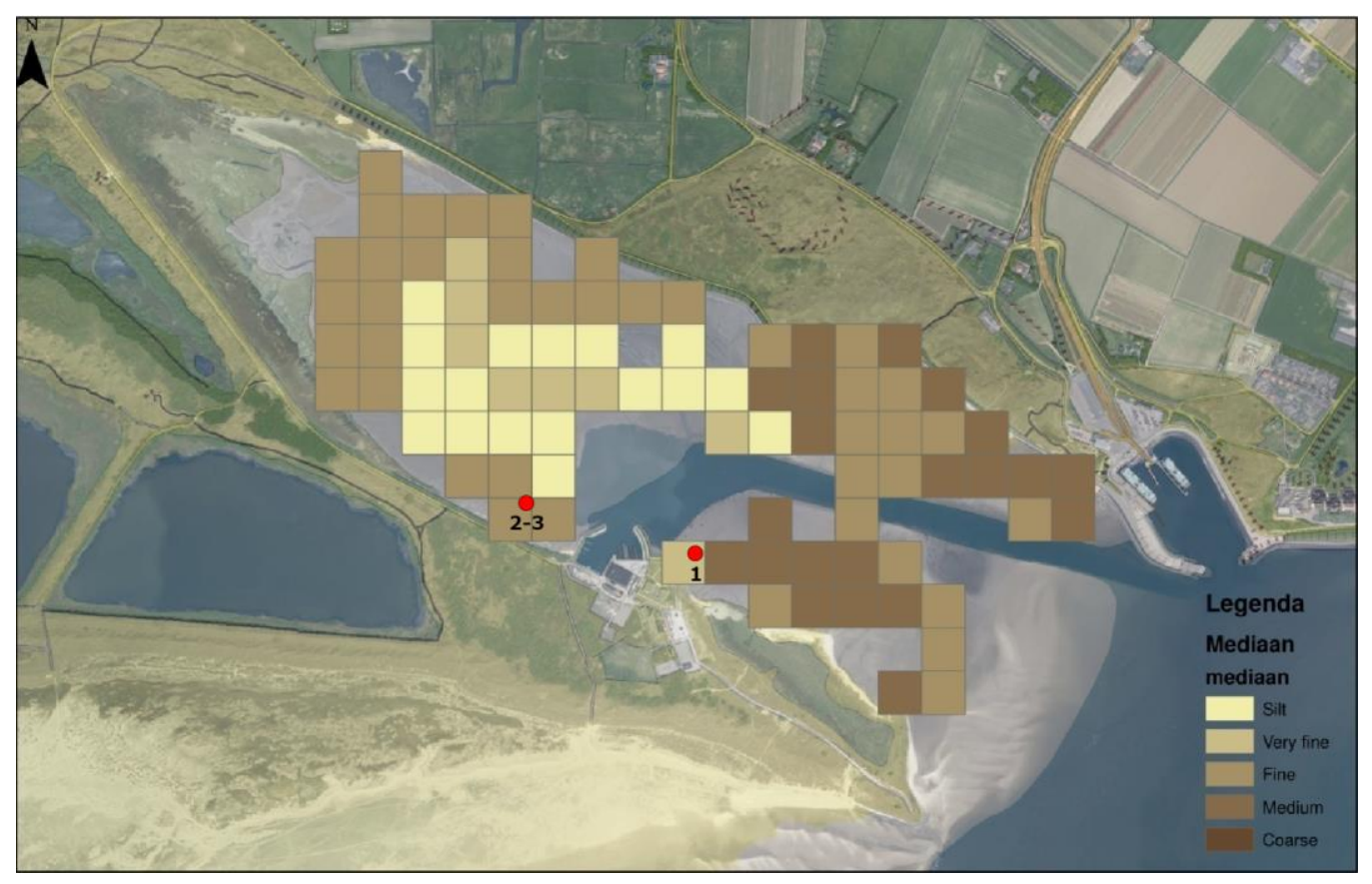

Figure 7 Mokbaai measurement locations with median grain size with contribution of mud in 5 classes ranging from 0-2 \% (yellow), 2-5\%, 5-20\%, 20-50\% and >50\% (dark brown). The mud contribution on the measurement positions varied from 2 to $5 \%$ (1, 2017-02-28) and 20-50\% (2\&3 2017-03-01/02).

\section{$2.4 \quad$ Pulse equipment}

\subsubsection{Electrode arrangement}

The set-up involved 3 pairs of conductors wired in parallel and spread out over an area of $4.5 \times 1 \mathrm{~m}$. The dimensions of the Delmeco conductor was $180 \mathrm{~mm}$ and $25 \mathrm{~mm}$ diameter and also used in earlier field strength measurements in the laboratory and at sea (de Haan et al., 2016; Soelaert et al., 2016). At both ends Delmeco isolator sections of 240 and $600 \mathrm{~mm}$ length were connected involving nylon discs of $70 \mathrm{~mm}$ diameter mounted at either ends of the conductor. The conductors were positioned at a distance of $325 \mathrm{~mm}$, equal to the distance tested in the WMR tank studies. At present the pulse wing trawls are set to a $420 \mathrm{~mm}$ electrode distance.

\subsubsection{Pulse settings \& control}

The array of three conductor pairs was wired in parallel to ensure all three conductor pairs would be subjected to the same pulse voltage excluding mutual exposure changes. The array was connected to a Delmeco pulse module system equivalent to the device applied in commercial pulse trawls, driving 
an electrode with 6 to 11 conductors. The pulse module and driver software were provided by Delmeco BV, Goes NL. The pulse module and power supply were built in an armoured waterproof PVC housing with an ethernet connection port to accommodate remote controlled operation and data logging. A Delmeco designed graphical interface (GUI) was installed on a WMR laptop to configure the pulse settings and monitor pulse parameters and overall performance.

In this report we refer all measured results, voltage, current and field strength, to the 0 to peak level ( ${ }^{\text {o-peak }}$ ). Field strength was tested as a function of the pulse amplitude to test the regression function. The maximum pulse amplitude was $60 \mathrm{~V}$, equal to the setting tested in WMR tank studies with a pulse frequency and pulse width set to the nominal ranges of respectively $40 \mathrm{~Hz}$ and $220 \mu \mathrm{s}$ (de Haan et al., 2016). The first experiment on the Neeltje Jan location involved a pulse amplitude range of 51 to $60 \mathrm{~V}$, on the second location a wider range of 40 to $60 \mathrm{~V}$. The pulse amplitude was controlled as a percentage of the output voltage and displayed as an output voltage ( $\mathrm{V}^{0}$-peak $)$ at the terminals of the pulse module. To exclude the contribution of cable-losses from these readings the voltage across the conductors was measured in the field before the start of the experiment (Table 1). In this report all voltage amplitudes refer to the voltage at the level of the conductor. As the Delmeco GUI readings of the output current to the conductors were based on an uncalibrated resistor shunt these data were only used as indicative measure for the total supplied current. The pulse equipment was remotely powered by using a $1 \mathrm{~kW}$ power engine.

Table 1 Pulse module voltage settings amplitudes measured at the conductors.

\begin{tabular}{|l|l|l|}
\hline Setting & $\begin{array}{l}\text { V } \\
\text { module }\end{array}$ & $\begin{array}{l}\text { V } \\
\text { conductor }\end{array}$ \\
\hline $100 \%$ & 64 & 60 \\
\hline $87 \%$ & 58 & 54 \\
\hline $75 \%$ & 53 & 50 \\
\hline $64 \%$ & 49 & 46 \\
\hline $50 \%$ & 43 & 40 \\
\hline
\end{tabular}

\subsection{Measurement equipment}

The analogue differential probe signals were digitised using modular CDAQ devices (National Instruments), which were plugged into a chassis supporting a maximum of 8 modules.

The first experiment at Neeltje Jans the 156 analogue signals (150 analogue probe signals and 3 differential current channels $\approx 6$ inputs) were divided over 5 CDAQ modules. Each of the 5 CDAQ modules supported a sample rate of $250 \mathrm{kHz}$ maximum. In this set-up 156 channels were shared over 5 modules, meaning 31 channels sequentially sampled at $250 \mathrm{kHz}$, resulting in $8 \mathrm{kHz}$ (8000 samples/S) per input channel. For the second trial on the Mokbaai location the number of CDAQ modules was increased to 7, which enabled a sample rate of $11 \mathrm{kHz}$ (11000 samples/S. Given the $2 \%$ duty cycle the pulse signal peaks was covered either by 160 samples ( $2 \%$ of 8000 ) of 220 samples ( $2 \%$ of 11000$)$. The CDAQ chassis was AC powered, while data transfer and pulse module control were managed via an ethernet connection to a laptop stationed further up shore. The data acquisition was managed by using a GUI based on Signal Express 2016 (Labview, National Instruments).

\subsection{Analysis procedure}

Maximum and minimum levels of field strength were assessed and taken as main representative of the field strength result. As first conditioning step DC-offsets were filtered out by use of an AC coupling conditioning routine in DiaDem (National Instruments). Any effect of the data conditioning on peak-to peak levels was checked to assure a zero-influence to the levels of the signal. Raw data series were observed on artefacts and distorted signals. Artefacts are expressed as high deviations between bipolar signal parts or significant difference in signal shapes and sorted as a pre-selection step. These artefacts are likely to refer to conductivity leakage paths along the probe shafts or overload conditions of the voltage input range limited to $+/-10 \mathrm{~V}$. Conditioned results containing artefacts were not used. 


\section{Results}

The field strength measurements were conducted on 14 and 15 December 2016 and continued from 28 February to 2 March 2017. Analysed trials reflect high-tide conditions and samples of water salinity and temperature were taken within a period of 5 to 10 minutes. The overview of analysed trial and environmental conditions are listed in Table 2.

Table 2 Timing and range of analysed trials with environmental conditions and water height.

\begin{tabular}{|c|r|r|r|r|c|}
\hline Date & $\begin{array}{c}\text { Start } \\
\text { Time }\end{array}$ & $\begin{array}{c}\text { Trial } \\
(\mathrm{nr})\end{array}$ & $\begin{array}{c}\text { Water } \\
\text { height } \\
(\mathrm{m})\end{array}$ & $\begin{array}{c}\text { Salinity } \\
(\mathrm{ppm})\end{array}$ & $\begin{array}{c}\text { Water } \\
\text { temperature } \\
\left({ }^{\circ} \mathrm{C}\right)\end{array}$ \\
\hline $2016-12-14$ & $13: 22$ & 4 & 1.9 & 31.8 & 7.8 \\
\hline & $13: 39$ & 6 & 1.9 & 31.8 & 7.8 \\
\hline $2016-12-15$ & $14: 40$ & 9 & 1.9 & 31.9 & 7.8 \\
\hline & $14: 58$ & 10 & 1.8 & 31.9 & 7.8 \\
\hline & $15: 58$ & 13 & 1.6 & 31.9 & 7.5 \\
\hline & $16: 05$ & 14 & 1.6 & 31.9 & 7.5 \\
\hline $2017-02-28$ & $20: 50$ & 3 & 1.2 & 29.1 & 5.4 \\
\hline & $22: 29$ & 13 & 1.2 & 29.1 & 5.4 \\
\hline $2017-03-01$ & $21: 48$ & 16 & 0.75 & 28.9 & 5.3 \\
\hline & $23: 30$ & 17 & 0.6 & 28.9 & 5.3 \\
\hline $2017-03-02$ & $21: 20$ & 6 & 0.75 & 29 & 5.6 \\
\hline & $22: 12$ & 10 & 0.8 & 29.2 & 5.4 \\
\hline
\end{tabular}

The different salinity/temperature conditions were also expressed in the supplied current to the conductors. In addition to this the peak current amplitude measured on the Neeltje Jans location had an instable behaviour, most likely related to power engine instability (Figure 8). As with field strength results the current readings refer to the peak values.
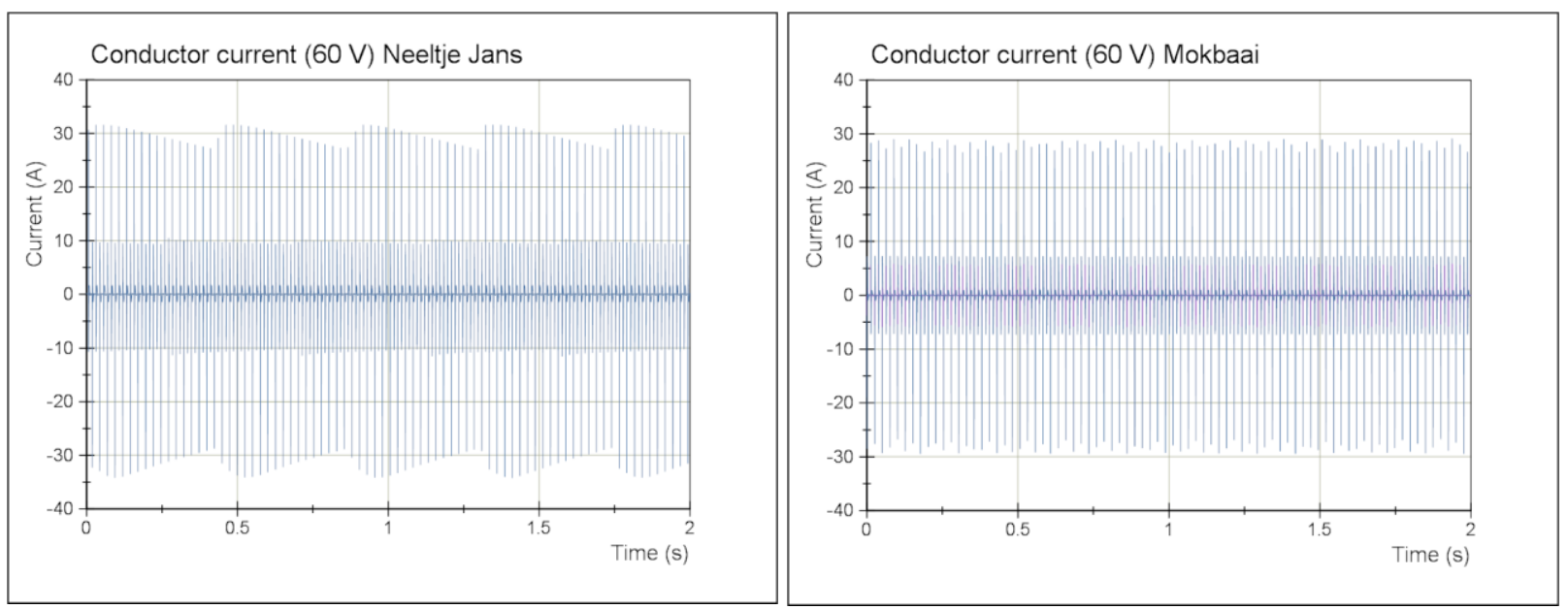

Figure 8 Conductor current signals measured on the two locations showing LF oscillations in the Neeltje Jans current pattern most likely due to instable behaviour of the power engine. The location with lower salinity (Mokbaai, Table 2) reflects a slightly lower current. 


\subsection{Field strength assessment \& justification}

Over the measured period the field strength signal amplitude was regular with the a similar LF ripple as found in the current signal (Figure 8). The example of Figure 9 shows the result before DC-offset filtering.

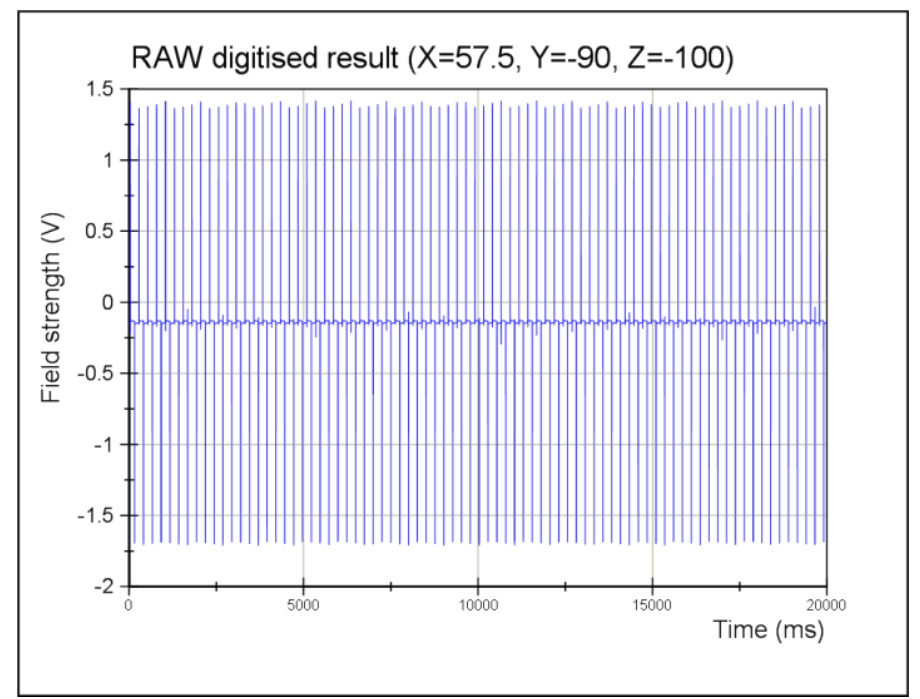

Figure 9 Typical digitised RAW field strength signal shape (2017-03-01) showing a negative DCoffset.

In Figure 10 the effects of $A C$ coupling to the $\delta$ between bipolar signals parts are shown as a function of the order of the input terminations of conductor A, B and C. The DC-offset had no fixed relation with the signal amplitude, but was relatively constant, so the effect on the outcome of field strength in the lower ranges of $\mathrm{Z}=+/-100$ and 200 was relatively high with a maximum of $4 \mathrm{~V} \cdot \mathrm{m}^{-1}$. When the pulse voltage increased to $60 \mathrm{~V}$ in some part of the signal input range artefacts were introduced, which did not occur at the lower voltage settings, likely to be linked to input overload or conductivity leakage paths along the probe shafts. These data could be kept unused as in most cases errors occurred only in the data of one of the three conductors.
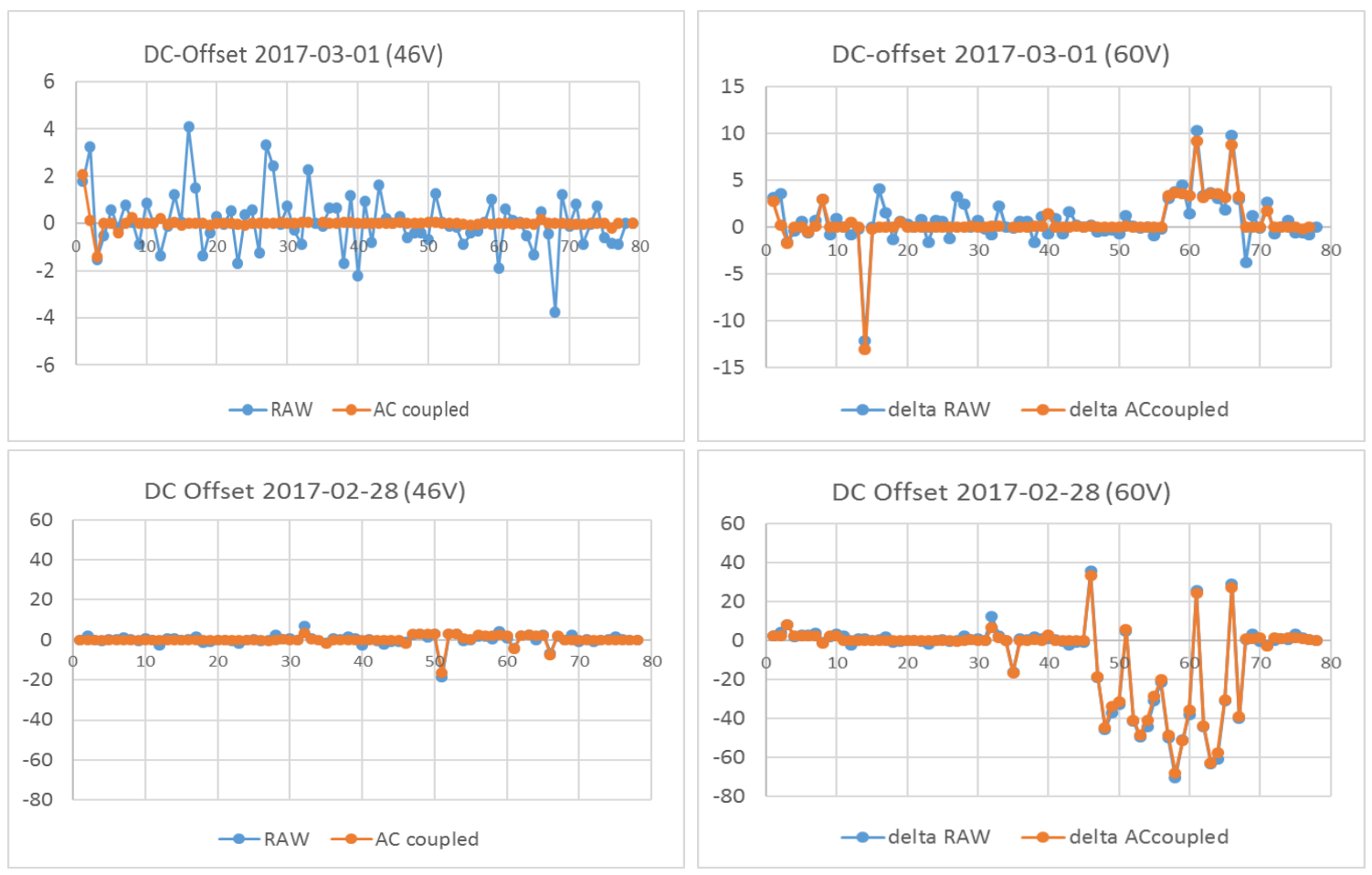

Figure 10a to d The effect of AC coupling to the RAW data and artefacts occurring at higher voltages. Numbers on the $X$ axis represent the order of input terminations (conductor $A, B, C$ ). 
Figure 11 shows an example of an artefact of the time series measured opposite conductor $B(X=57.5$, $Y=45, Z=-100$ ). In this example the measured bipolar amplitudes were 4.5 and $-3.0 \mathrm{~V}$, expressing a field strength of 101 and $84 \mathrm{~V} \cdot \mathrm{m}^{-1}$. As these artefacts occurred in all levels of $Z$ results data of conductor $B$ were excluded from the analysis. Data were processed according the equation ( $\mathrm{V}^{\mathrm{p}}$ $\left.{ }^{\mathrm{p}}\right) / 2+\mathrm{V}^{0+\mathrm{p}}$. In this model the bipolar part containing the complete amplitude including the peak ripple was averaged with the (peak to peak)/2 outcome. When both bipolar parts are in the same range this extra weighting has a minor effect (Figure 12b, right), when the effect increased (Figure 12a left) additional choices were made either to use the data with a precaution or in addition the linear regression produced a more accurate match.

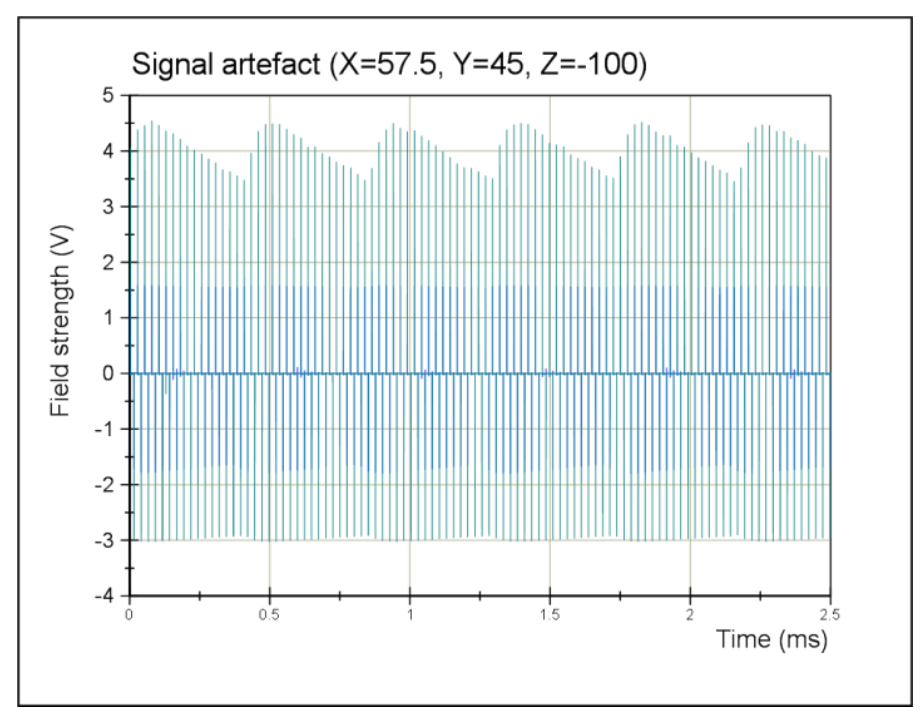

Figure 11 Time series of a field strength signal indicating an unexplained signal artefact, which cannot lead to a single result and so these data were excluded from the analysis.

When the $\delta$ peak of positive and negative signal part was minor, the effect on the average estimate was minor likewise (Figure 12b). Artefacts are expressed as out-range values (with leakage paths as background) producing non-overlapping results (Figure 12a).
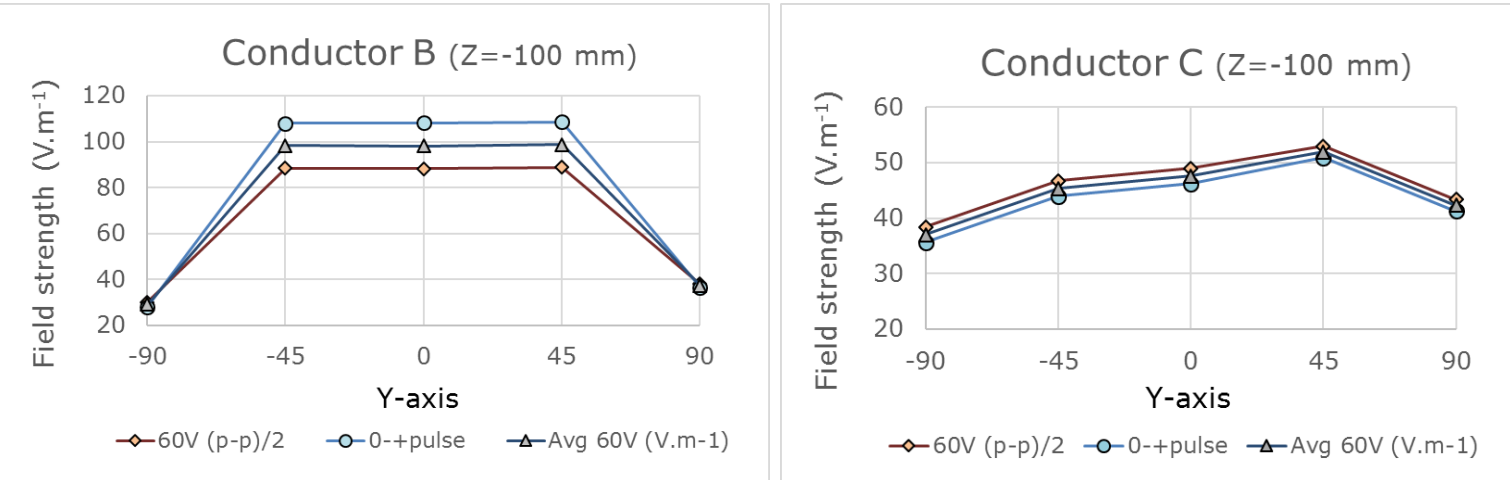

Figure 12a \& b Field strength around two conductors measured on the compact sandy layer (Neeltje Jans 2016-12-14) for $Z=-100(Y=+90$ to -90 and $X=57.5 \mathrm{~mm}$ ) showing a significant difference between bipolar parts and the background of not using the data of conductor $B$.

The position $X=57.5$ and $Y=0$ opposite the $A$ conductor contained a positioning error. One of the probes at position $\mathrm{Y}=0$ did not reach the required depth. This was the only positioning error in both experiments. In all other cases probes were positioned smoothly without encountering obstacles of any kind that could affect the referred position or depth in the sediment. 


\subsection{Results on a compact sandy layer (Neeltje Jans)}

The conditions during the first measurements were excellent with no wind and light freezing temperatures between 0 to $-2{ }^{\circ} \mathrm{C}$. The results reflect a salinity condition of 31.8 to $31.9 \mathrm{ppm}$ and a water temperature of 7.5 to $7.8^{\circ} \mathrm{C}$. The first day (2016-12-14) field strength was measured in short range from the conductor $(X=57.5$ and $Y=+90$ to -90$)$. A single probe at position $Y=-90$ was jammed by an obstacle in the sediment and did not reach the required depth. The results of this probe channel were not used. The second day (2016-12-15) the measurements involved two pairs (B \& C), with two distance ranges of $X$ measured, close range $(X=57.5)$ and half-range $(X=162.5)$. Field strength in close range $(X=57.5)$ peaked not always opposite the centre of the conductor $(Y=0)$, but peaks also occurred at positions aside of the centre $Y=0$, at $Y=+45$ or $Y=-45$. The maximum field strength results (Table 3) reflect to the positions of $X, Y$ and $Z$. The results replicated within $4 \mathrm{~V} \cdot \mathrm{m}^{-1}$ between different conductors and after rebuilding the measurement system the next day (2016-12-15).

The uncertainty of the averaged result related to $\delta$ peak of signal amplitudes and varied between 2 to $6 \%$. At seabed level $Z=0$ these findings increased to $3.2 \mathrm{~V} \cdot \mathrm{m}^{-1}$ at 50 and $54 \mathrm{~V}$ and $19 \mathrm{~V} \cdot \mathrm{m}^{-1}$ max at $60 \mathrm{~V}$. In these cases the linear extrapolated trends are a better match. Such an example is shown in Figure 14 with the $X=57.5$ and $Z=0$ findings at two cases of $60 \mathrm{~V}$, where the lower outcome of 212 $\mathrm{V} . \mathrm{m}^{-1}$ did not match the linear trend. Note that this outcome of two pairs of conductors at $1.5 \mathrm{~m}$ distance is a close match.

Table 3 Selection of highest field strength at short and equal distance from the conductors on the Neeltje Jans location. Results reflect the peak value found in the range of $Y=+45$ to -45 .

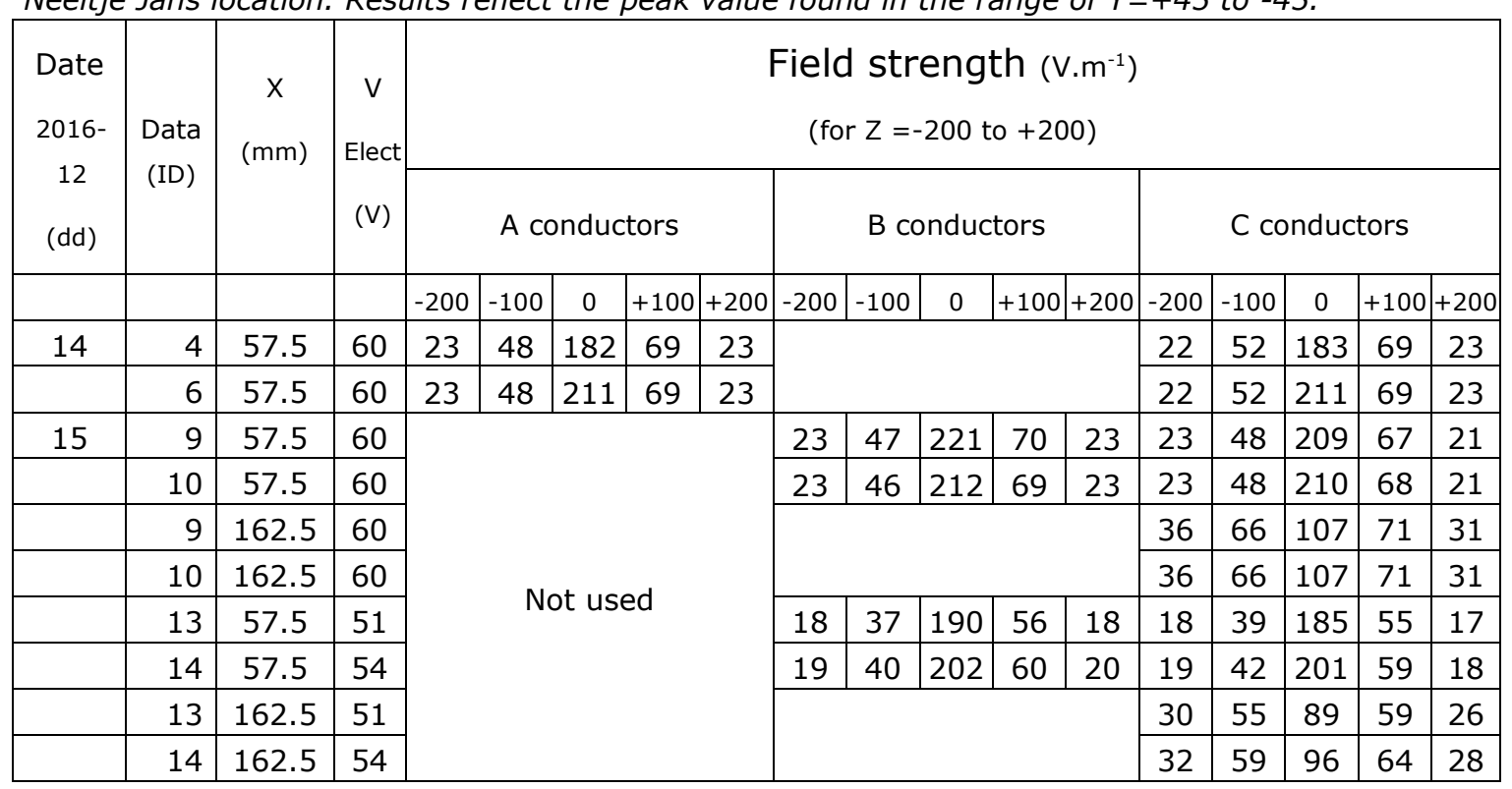

\subsection{Results on a mixture of sand and mud (Mokbaai)}

The measurements conducted in 2017 refer to the western shore of the Mokbaai in Texel at the "Joost Dourlein" mariner base. This location was sheltered against wind from west to north. At the time of the measurements conditions were fine, but the measured location was unsheltered for swell and under influence of Marsdiep sea state conditions. These effects were highest on the location west of the entrance of the Joost Dourlein harbour (trial 2017-02-28).

The location east of the harbour entrance (trial 2017-03-01/02) was sheltered by the harbour barriers, while the weather conditions further improved. The overview of measurement dates, conditions and measured positions are listed in the overview of Table 4. 
Table 4 Selection of highest field strength at short and mid-ranges of $X$ from the conductors on the Mokbaai location. Results reflect the peak value found in the range of $Y=+45$ to -45 .

\begin{tabular}{|c|c|c|c|c|c|c|c|c|c|c|c|c|c|c|c|c|c|c|}
\hline \multirow{3}{*}{$\begin{array}{l}\text { Date } \\
2017 \\
(\mathrm{~mm}- \\
\text { dd) }\end{array}$} & \multirow{3}{*}{$\begin{array}{c}\text { Data } \\
\text { (ID) }\end{array}$} & \multirow[t]{3}{*}{$\begin{array}{c}X \\
(m m)\end{array}$} & \multirow{3}{*}{$\begin{array}{c}V \\
\text { Elect } \\
(\mathrm{V})\end{array}$} & \multicolumn{15}{|c|}{$\begin{array}{l}\text { Field strength (V.m-1) } \\
\qquad \text { (for } Z=-200 \text { to }+200 \text { ) }\end{array}$} \\
\hline & & & & \multicolumn{5}{|c|}{ A conductors } & \multicolumn{5}{|c|}{ B conductors } & \multicolumn{5}{|c|}{ C conductors } \\
\hline & & & & -200 & -100 & 0 & +100 & +200 & -200 & -100 & 0 & +10 & +200 & -200 & -100 & 0 & +100 & +200 \\
\hline \multirow[t]{2}{*}{$02-28$} & 8 & 57.5 & 60 & 35 & 57 & 201 & 60 & 21 & 32 & 52 & 238 & 75 & 25 & 29 & 64 & 229 & 48 & 19 \\
\hline & 9 & 57.5 & 60 & 32 & 58 & 215 & 61 & 21 & 37 & 52 & 219 & 75 & 25 & 27 & 65 & 222 & 48 & 19 \\
\hline \multirow[t]{4}{*}{ 03-01 } & 8 & 57.5 & 60 & 23 & 42 & 227 & 64 & 21 & & & & & & 22 & 60 & 224 & 71 & 24 \\
\hline & 16 & 57.5 & 60 & 26 & 42 & 207 & 63 & 21 & & & & & & 22 & 60 & 238 & 71 & 24 \\
\hline & 8 & 162.5 & 60 & 34 & 62 & 97 & 66 & 29 & & & & & & & & & & \\
\hline & 16 & 162.5 & 60 & 34 & 62 & 97 & 66 & 29 & & & & & & & & & & \\
\hline $03-02$ & 10 & 57.5 & 60 & & & & & & 24 & 49 & 239 & 68 & 23 & 12 & 54 & 228 & 74 & 21 \\
\hline
\end{tabular}

\subsection{Summarised Results}

Field strength did not always peak opposite the centre of the conductor $(Y=0)$ (Figure 20 and 21 , Table $3 \& 4)$, but reflect to three positions of $Y$ around the centre of a conductor $(Y=-45 m m, Y=0, Y=$ $+45 \mathrm{~mm})$. The lowest field strength of this experiment was found opposite the isolator $(X=57.5, Y=-$ $180 \mathrm{~mm})$. Results observed along the X-axis $(57.5 \& 162.5 \mathrm{~mm}$ ) show that field strength at the vertical boundaries $\left(Z=+/-200 \mathrm{~mm}\right.$ ) reduced from $36 \mathrm{~V} \cdot \mathrm{m}^{-1}$ at equal distance from the conductors $(X=162.5 \mathrm{~mm})$ to $23 \mathrm{~V} \cdot \mathrm{m}^{-1}$ towards the conductor $(X=57.5 \mathrm{~mm})$.

When the vertical observed range is narrowed $(Z=-/+100 \mathrm{~mm})$ the maximum mid-range field strength at the positions of $X$ were similar and increased to $66 \mathrm{~V} \cdot \mathrm{m}^{-1}$ for both levels of $Z$, but was higher and more irregular $\left(48-75 \mathrm{~V} \cdot \mathrm{m}^{-1}\right)$ on the location with a sand an mud sediment. Field strength measurements in the compact sandy sediment (Neeltje Jans) showed low variation and replicated on different locations and after rebuilding the equipment the next day within $4 \mathrm{~V} . \mathrm{m}^{-1}$. In the less compact sediment of sand and mud (Mokbaai), the results varied between replicates and also varied significantly between conductor pairs of a single experiment.

Table 5 Maximum field strength results $\left(\mathrm{V} . \mathrm{m}^{-1}\right)$ at $60 \mathrm{~V}$ conductor voltage at listed for the distance ranges of $X$. The value " $n$ " refers to the number of observations.

\begin{tabular}{|c|c|c|c|c|c|c|c|c|c|}
\hline \multicolumn{1}{|c|}{ Close range $\mathrm{X}=57.5$} & \multicolumn{6}{|c|}{ Equal distance $\mathrm{X}=162.5$} \\
\hline & $\begin{array}{c}\text { Mokbaai } \\
(1)\end{array}$ & $\begin{array}{c}\text { Neeltje } \\
\text { Jans } \\
(8)\end{array}$ & $\begin{array}{c}\text { Mokbaai } \\
(9)\end{array}$ & $\begin{array}{c}\text { Neeltje } \\
\text { Jans } \\
(1)\end{array}$ & $\begin{array}{c}\text { Neeltje } \\
\text { Jans } \\
(1)\end{array}$ & $\begin{array}{c}\text { Neeltje } \\
\text { Jans } \\
(1)\end{array}$ & $\begin{array}{c}\text { Mokbaai } \\
(1)\end{array}$ & $\begin{array}{c}\text { Mokbaai } \\
(1)\end{array}$ & $\begin{array}{c}\text { Mokbaai } \\
(1)\end{array}$ \\
\hline Z axis & $\mathrm{Y}=-180$ & $\begin{array}{c}\mathrm{Y}=-45 \text { to } \\
+45\end{array}$ & $\begin{array}{c}\mathrm{Y}=-45 \text { to } \\
+45\end{array}$ & $\mathrm{Y}=-45$ & $\mathrm{Y}=0$ & $\mathrm{Y}=+45$ & $\mathrm{Y}=-45$ & $\mathrm{Y}=0$ & $\mathrm{Y}=+45$ \\
\hline+200 & 11 & $21-23$ & $19-25$ & 31 & 26 & 22 & 27 & 29 & 27 \\
\hline+100 & 19 & $67-70$ & $48-75$ & 71 & 66 & 55 & 61 & 66 & 60 \\
\hline 0 & 22 & 220 & $263 *$ & 104 & 107 & 98 & 97 & $* *$ & 95 \\
\hline-100 & 18 & $46-52$ & $42-65$ & 58 & 64 & 66 & 62 & 59 & 59 \\
\hline-200 & 14 & $22-23$ & $12-37$ & 26 & 31 & 36 & 34 & 28 & 27 \\
\hline
\end{tabular}

* finding exceeded the voltage input ranges and is the extrapolated result of the linear conductor voltage trend.

** the results not used (unexplained error), all other results for $Y$ confirmed the Neeltje Jans trend. 


\subsection{Results of both sediment conditions}

As indicated by the conductivity measurements (Table 2) the different conductivity on both locations was also expressed in the supplied current. On the Neeltje Jans location the conductor current at maximum voltage setting ( $60 \mathrm{~V}$ ) was $32.9 \mathrm{~A}$, while on the Mokbaai location the current was $28.5 \mathrm{~A}$. Unfortunately, the current probes of two of the three conductor pairs failed with unknown reason. Although a single current is presented as reference, the total current monitored on the pulse driver GUI showed that the total current supplied was on average three times the value of this single presented result. Both graphs show that the current values are linearly proportional to the supplied conductor voltage and that this trend was valid for the full conductor voltage range tested (Figure 13).

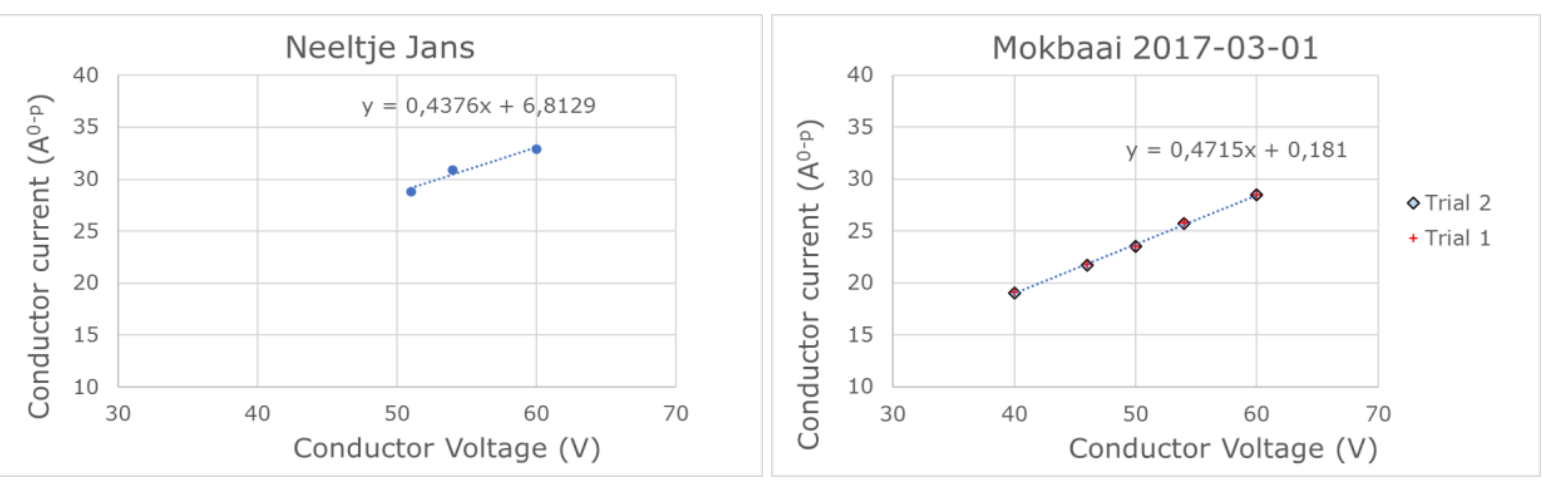

Figure 13 Conductor current as a function of conductor voltage.

The DC-offsets were highest at the $60 \mathrm{~V}$ conductor voltage (Figure 10a-d), indicating measurement artefacts due to input overload. As these artefacts did not occur at lower conductor voltage settings field strength for the $60 \mathrm{~V}$ range was also extrapolated from the linear trend. For the Neeltje Jans experiment extrapolation was tested for only three settings (51, 54 and $60 \mathrm{~V}$ ). The Mokbaai experiments involved a wider range of 5 settings ( 40 to $60 \mathrm{~V}$ ). Field strength at seabed level $(X=57.5$, $Z=0)$, measured at a shifted range of $Y(-45$ to $-180 \mathrm{~mm})$ shows the decline towards the isolator (Figure 14). The $\mathrm{Y}-90$ position is opposite the junction of isolator and conductor. Field strength at $\mathrm{Y}$ 180 ranged from 15 to 22 V.m $\mathrm{m}^{-1}$ for the tested conductor voltage range.

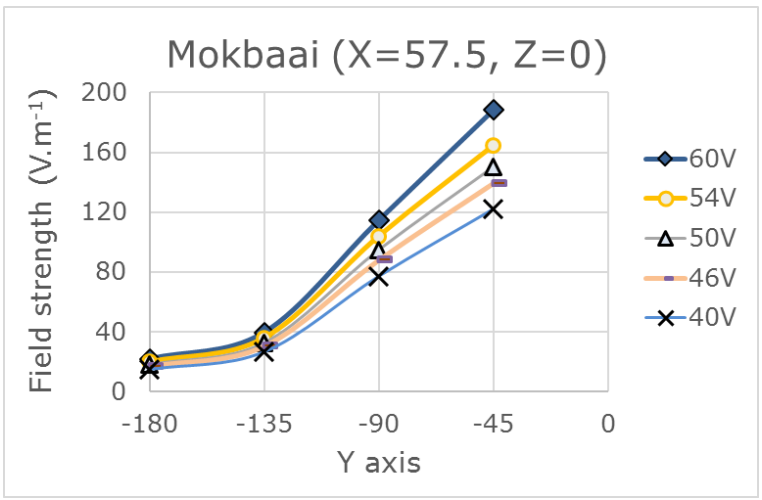

Figure 14 Field strength as a function of conductor voltage for $X=57.5, Y=-45$ to $-180 \mathrm{~mm}$ and $Z=0$, reflecting the $Y=$ range towards the isolator $(Y-180)$.

The results for $\mathrm{Y}=0$ position were discarded as one of the probes hit an obstacle and could not be positioned at the required depth.

Results of the Mokbaai trial (2018-03-02) show that the outcome of two adjacent conductor pairs significantly differed and that the highest conductor voltage range was not accurately measured (Figure $15 \mathrm{a} \& \mathrm{~b}$ ). The linear extrapolated results for the field strength at $60 \mathrm{~V}$ were respectively 266 V. $\mathrm{m}^{-1}$ (Figure 15a) and $216 \mathrm{~V} \cdot \mathrm{m}^{-1}$ (Figure 15b). This example shows that sediment conditions on this location may have varied locally at distance ranges as short as $1.5 \mathrm{~m}$. 


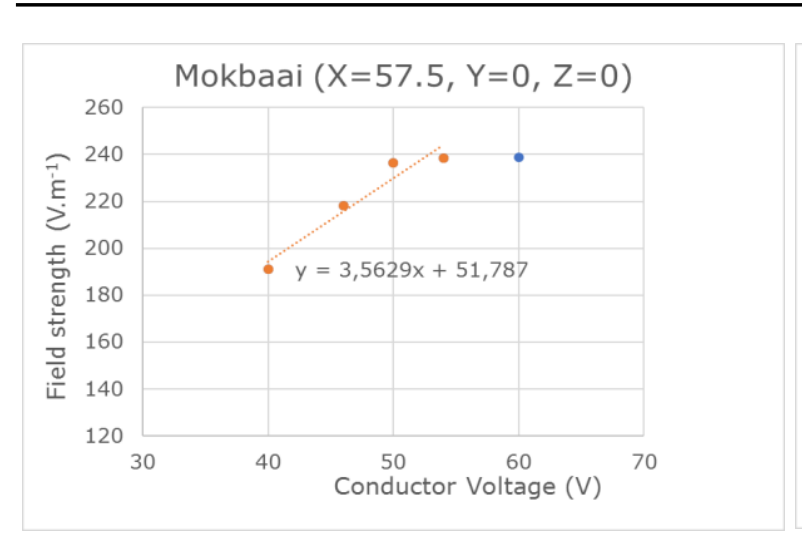

a)

\section{Figu}

Field strength of a single experiment measured on 2017-03-02 with two conductor pairs at $1.5 \mathrm{~m}$ distance, showing a linear function with the lower conductor voltage ranges and input overload at highest voltage range $(60 \mathrm{~V})$ indicating conductivity changes within the tested area range $(1.5 \times 0.4 \mathrm{~m})$.

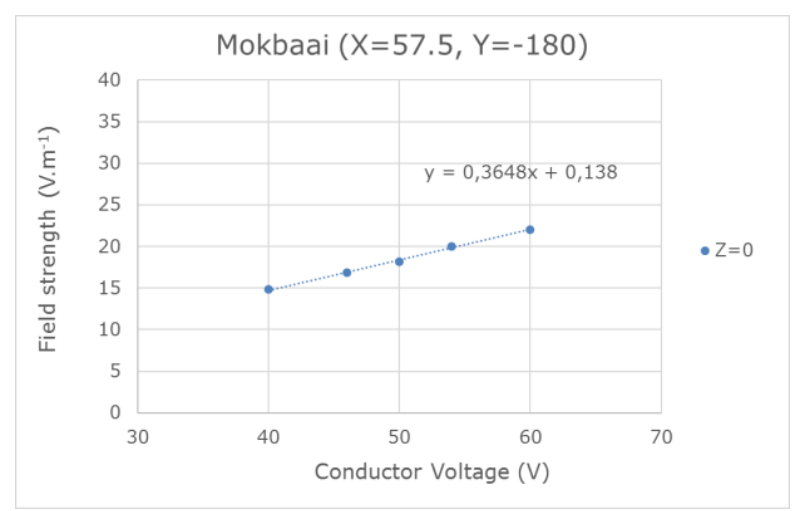

As shown in Figure 14 field strength at seabed level $(Z=0)$ reduced along the $Y$-axis towards the isolator $(Y=-180)$. The results of the other levels of $Z$ confirm that field strength opposite the isolator $(\mathrm{Y}=-180 \mathrm{~mm}$ ) still related linearly to conductor voltage although the slope of the regression is not steep (Figure $16 a, b$ and $c$ ).
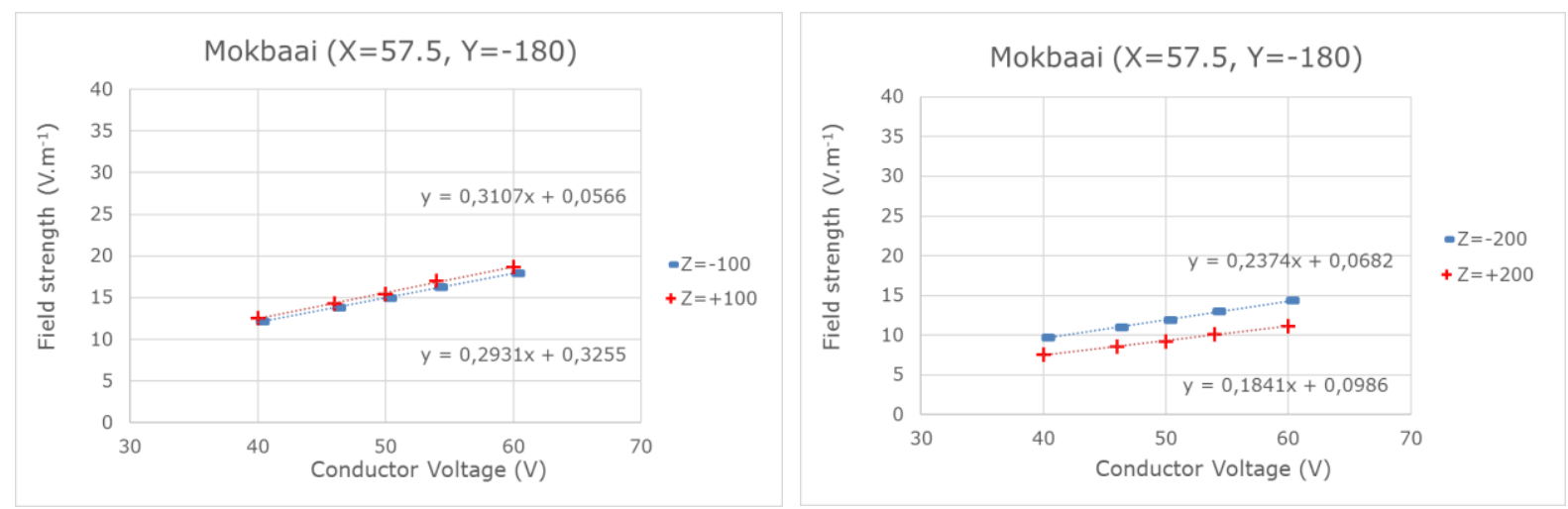

Figure 16a, b and c Field strength opposite the isolator $(X=57.5, Y=-180)$ for 5 levels of $Z$ showing the field strength decreased at the boundaries of $Z$, but field strength still reflects the tested conductor voltage range.

In the next section the listed results are visualized and compared per location/sediment condition for each level of Z. As first step two conductor pair results of the Neeltje Jans experiment are shown (Figure 17) and one of these compared to a Mokbaai result (Figure 18). The results for $Z=0$ show the $60 \mathrm{~V}$ is not accurately produced (voltage input range overflow). As shown in Table 3 the results of the compact sandy layer between two conductor pairs (B \& C) are a close match (Figure 17). A similar result was also found in a single Mokbaai result (Figure 18). This graph shows that for this conductor pair the results for $Z=-100 /+100$ and $-200 /+200$ are more or less in the same range.

However, results of the other conductor pair at $1.5 \mathrm{~m}$ distance show that this previous match is lost (Figure 19). These examples illustrate that significant differences may occur within a range of $1.5 \mathrm{~m}$. In the case of Figure 19 field strength in the sediment $(Z=-200)$ was significantly higher than above the bottom $(Z=+200)$, while at other levels for $Z$, in particular for $Z=0$ the contribution was much lower. 

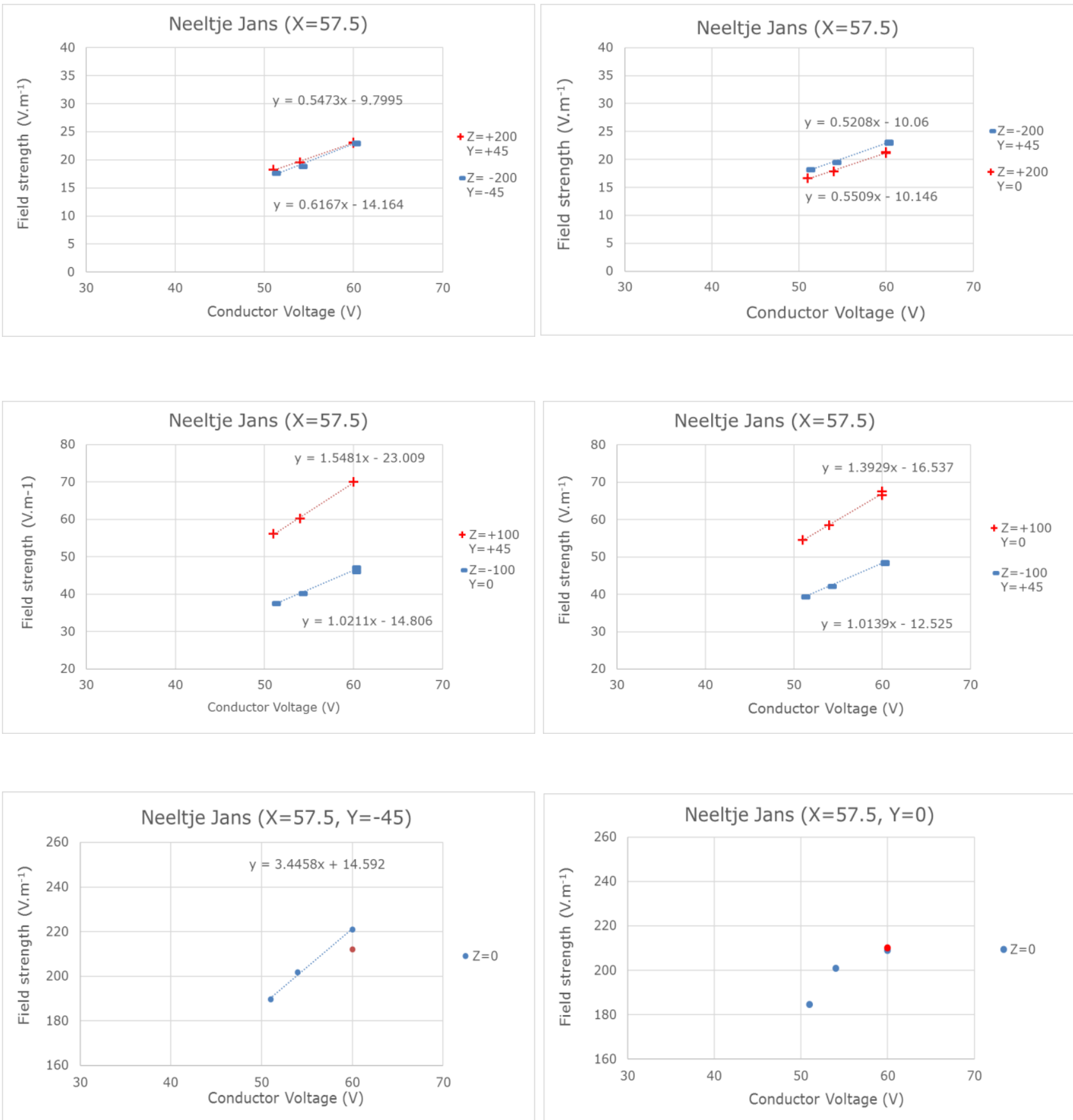

Figure 17 Field strength results of a single experiment as a function of conductor voltage (51, 54 and $60 \mathrm{~V}$ ) for two pairs of conductors positioned at a distance of $1.5 \mathrm{~m}$ on a compact North Sea type of sandy stratum at the borders of the Neeltje Jans outer harbour (2016-12-15). The outcome for two conductors replicates indicating conductivity in the sediment did not vary between layers at different positions, but results at highest conductor voltage were not accurately measured. 

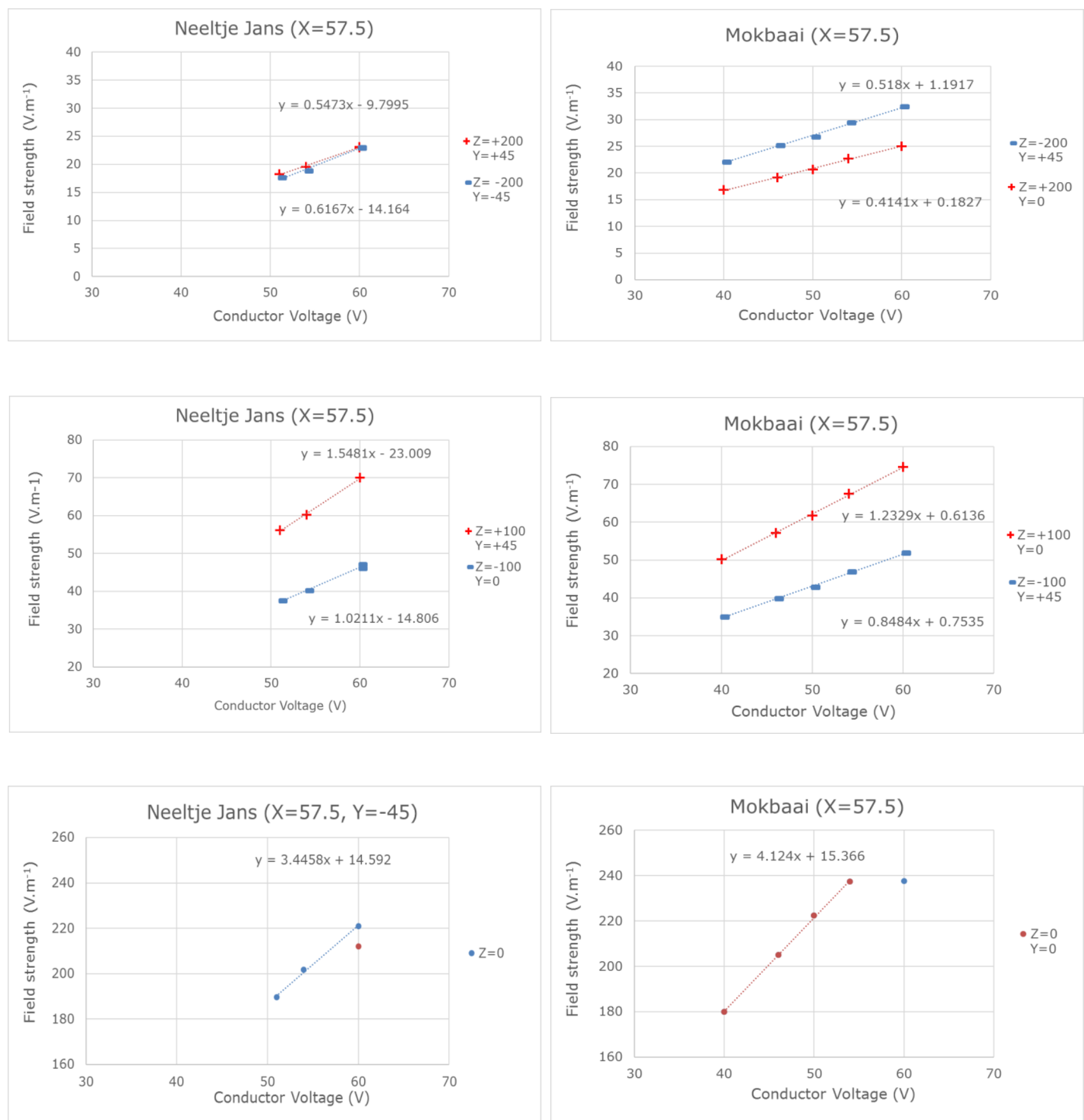

Figure 18 Field strength results of two different sediment types compared (compact North Sea sand, Neeltje Jans 2016-12-15) and a mixture of sand \& mud (Mokbaai, 2017-02-28). In this example the results of different locations compared, although field strength in the muddy layer was slightly higher. 

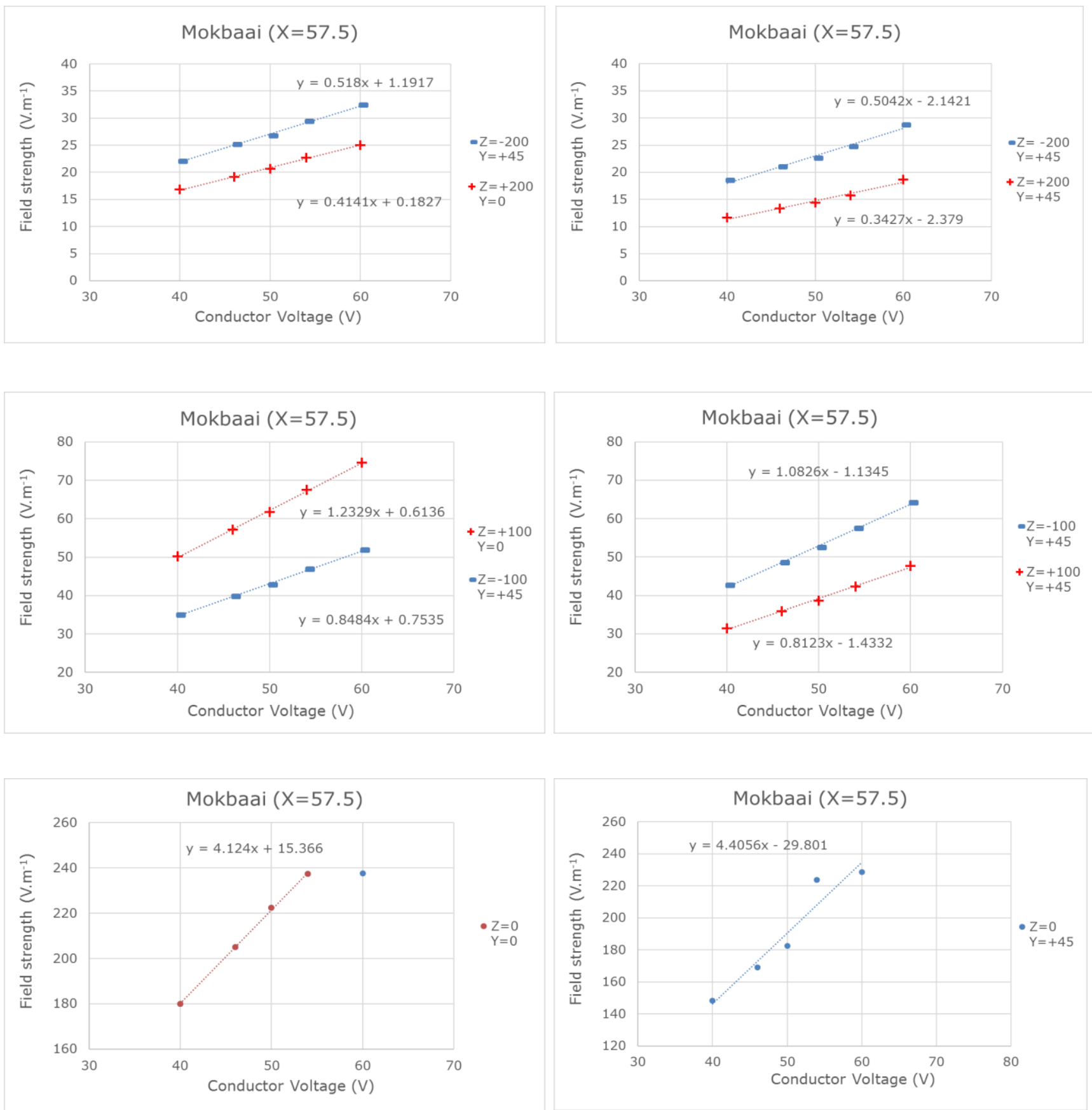

Figure 19 Field strength results of a single experiment comparing two pairs of conductors positioned at a distance of $1.5 \mathrm{~m}$ on a layer of sand and mud (Mokbaai, 2017-02-28). The results show that field strength may differ at short ranges as small as $1.5 \mathrm{~m}$, and that field strength in the sediment exceeded the values in the water volume at similar ranges from the seabed. 

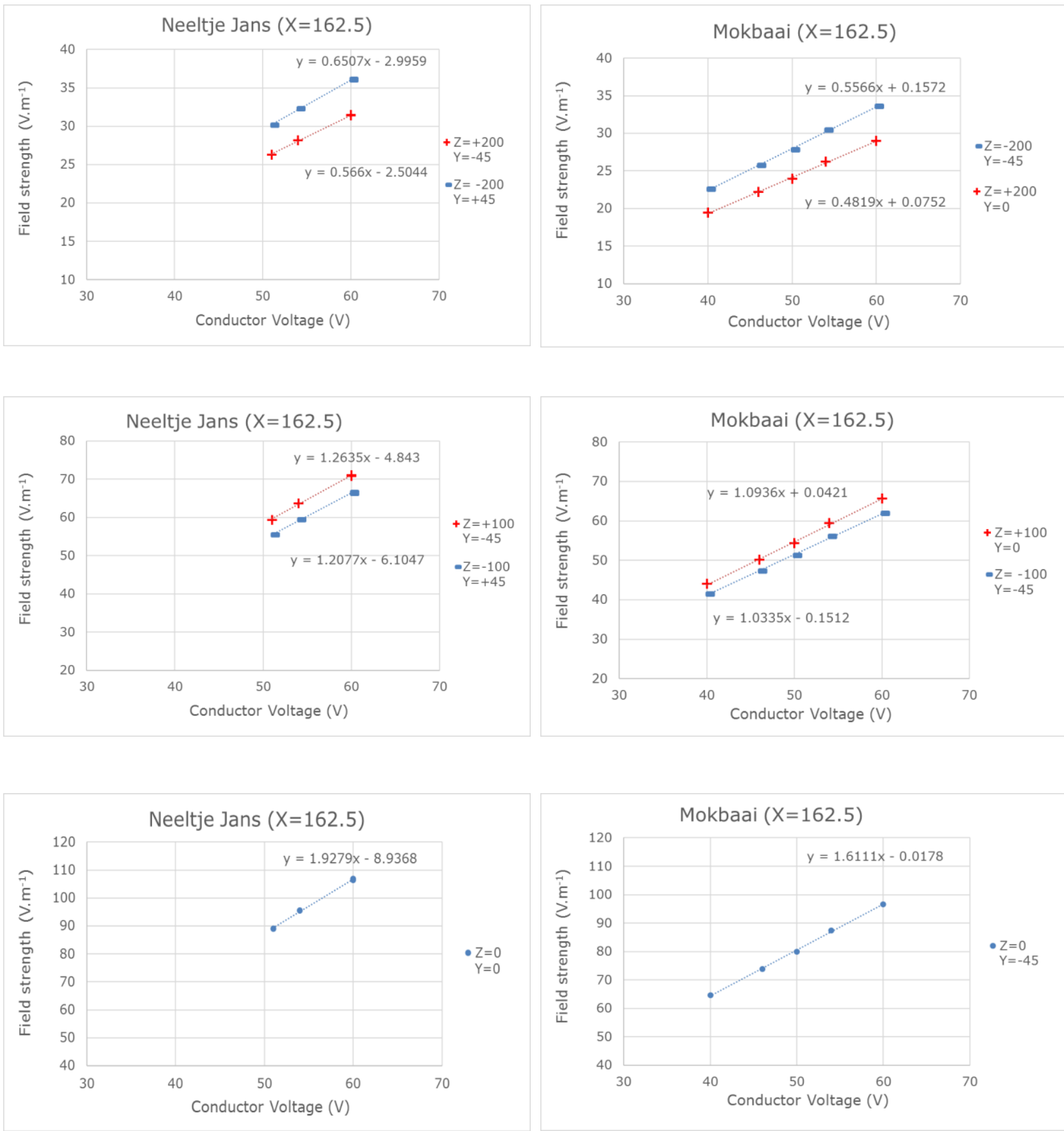

Figure 20 Field strength results measured at equal distance $(X=162.5 \mathrm{~mm})$ from a conductor pair for both sediment types.

The field strength on the vertical axis of $Z$ of both locations measured at equal distance from a pair of conductors ( $X=162.5 \mathrm{~mm}$ ) were in a comparable range accept for the $Z=0$ case (Figure 20). Also in this test the field strength peaked not opposite the centre of the conductor but varied alongside the conductor between $Y=+45$ to -45 and as well as along the vertical axis $Z$. A common observation for both locations is that field strength at the boundaries of the vertical axis $Z$ was highest in the sediment.

Field strength results of both locations are in the same range. The lower result at $Y=0$ at the Mokbaai location (Figure 21 ) was only found at seabed level $(Z=0)$ and not at the other levels of $Z$. 

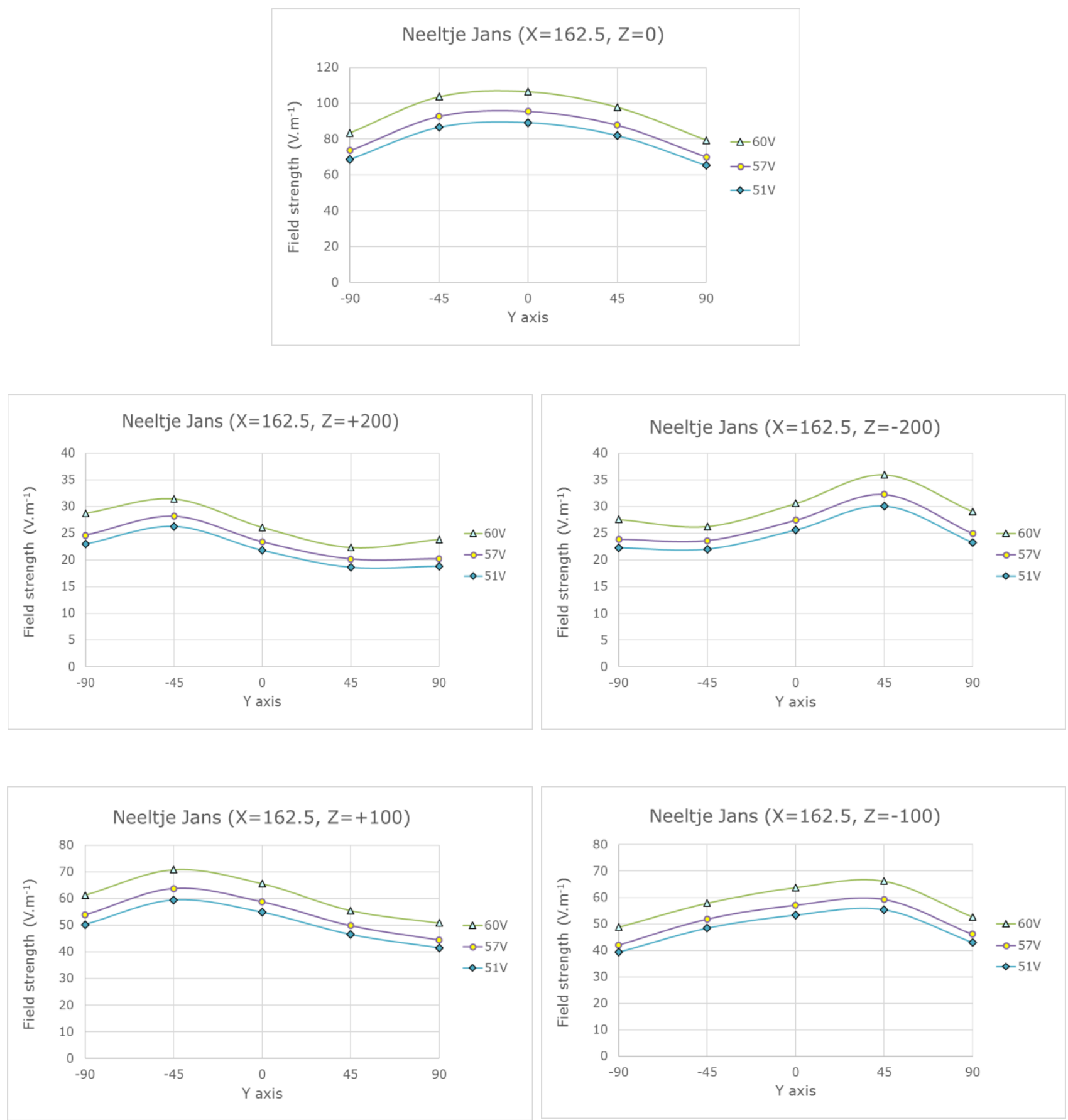

Figure 20 Field strength measured at Neeltje Jans for all five levels of $Z$ as a function of conductor voltage measured at equal distance of a pair of conductors ( $Y=-90$ to $+90 \mathrm{~mm})$. 

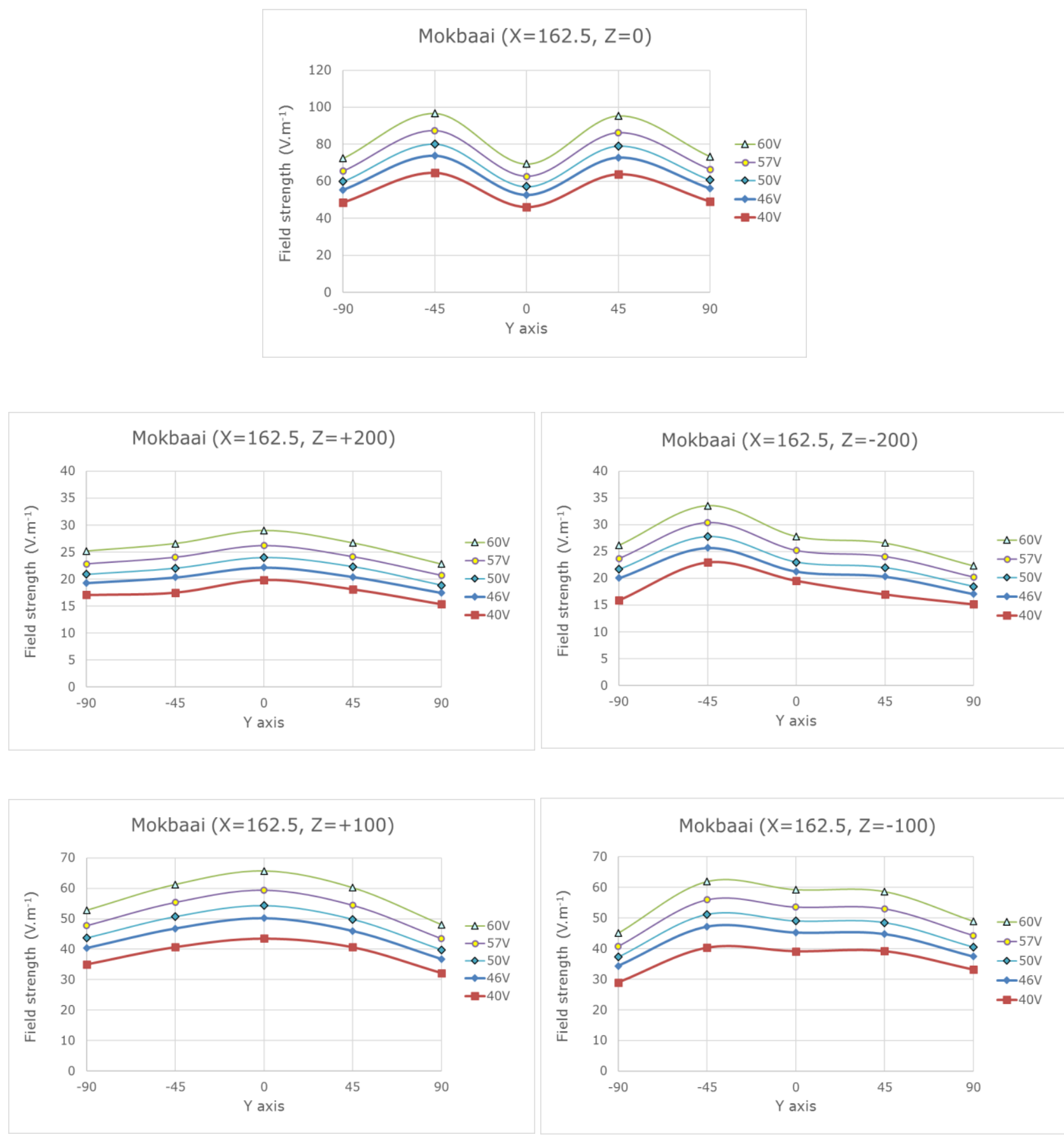

Figure 21 Field strength measured at Mokbaai for all five levels of $Z$ as a function of conductor voltage measured at equal distance of a pair of conductors $(Y=-90$ to +90$)$. The artefact at $Z=0 / Y=0$ is an underestimate, as results at other levels of $Z(+/-100$ an $Z+/-200 \mathrm{~mm})$ show the expected trend towards the center position $Y=0$. 


\section{Conclusions}

The experiment introducing a sediment layer showed that it did not reduce field strength found in tank studies. Field strength evenly distributed in the water volume and sediment, and was even higher at the vertical boundaries at equal distance of the conductors.

Field strength had a linear relation with the conductor voltage, but the regression varied with the level of $Z$ and in close range the slope of the regression declined proportional towards the boundaries of the vertical range $(Z=+/-200 \mathrm{~mm})$, indicating the contours of the electric field. At the boundaries of the vertical range field strength at equal distance of the conductor reduced with $26 \%(Z=+200 \mathrm{~mm})$ and $36 \%(Z=-200)$ towards the conductor $(X=57.5)$. Field strength observed on the $Y$ and $Z$-axis did not always peaked opposite the center of the conductor but also at positions aside $(Y=+/-45 \mathrm{~mm})$.

Compact sandy layer

At the vertical boundaries of $Z(+/-200 \mathrm{~mm})$ field strength at equal distance of a pair of conductors $(X=162.5)$ distributed almost evenly and peaked at $36 \mathrm{~V} \cdot \mathrm{m}^{-1}$ in the sediment and $31 \mathrm{~V} \cdot \mathrm{m}^{-1}$ in the water volume. At these vertical boundaries of $Z$ field strength reduced towards the conductor to 23 $V \cdot \mathrm{m}^{-1}(X=57.5 \mathrm{~mm})$. When observed in a narrowed range $(+/-100 \mathrm{~mm})$ field strength increased a factor 2 (70 V.m-1 versus $64 \mathrm{~V} . \mathrm{m}^{-1}$ ) was regular for the observed ranges of $X(57.5$ and $162.5 \mathrm{~mm}$ ) and slightly higher in the water volume.

Mixed layer of sand and mud

The results did compare to the results on the compact sandy layer, but had a higher variability and differed between conductor pairs at ranges as short as $1.5 \mathrm{~m}$. Field strength in the sediment exceeded the values in the water volume at similar ranges from the seabed.

The new method of sampling simultaneously on different locations and levels proved to be feasible and extended the methods of measuring field strength in the sediment. 


\section{Discussion}

There is no literature available to discuss the present results against other publications than those of earlier WMR tanks studies in the period 2006 to 2015. A common observation is that field strength did not reduce when a sediment layer replaced the artificial bottom of a tank. In spite of differences with tank studies, on position references, salinity and a conductive sediment layer, the present results confirm the earlier findings. On both locations field strength evenly distributed in the water volume and sediment. At equal distance a pair of conductors field strength in the sediment was higher in the sediment, even on the $0.3 \mathrm{~m}$ compact sandy on top of solid asphalt. The differences between the tested locations are expressed in the results, with higher deviations on the layer of mud and sand (Figure 19). Values found on the compact sediment (Table 3, Figure 17) replicated on tested positions of a single experiment and when the equipment was rebuild the next day.

Close range $(X=57.5)$

Field strength at seabed level did compare to the values found in tank studies (de Haan et al., 2016). Tank studies of similar pulse hardware observed $224 \mathrm{~V} \cdot \mathrm{m}^{-1}(X=87, Z=0)$, while in this study values ranged from 220 to $260 \mathrm{~V} \cdot \mathrm{m}^{-1}$ at closer range of the conductor $(X=57.5 \mathrm{~mm})$. The level of the conductor relative to the bottom level differed with $22 \mathrm{~mm}$. Nylon disks of $70 \mathrm{~mm}$ at both ends of the conductor lifted the conductor to $Z=+35 \mathrm{~mm}$ above the tank bottom, but were in the sediment in the present set-up (Figure 4). Field strength at seabed level on the mixed layer of mud \& sand varied between conductor pairs and replicates and was more stable on the compact sandy layer.

Equal distance range $(X=162.5 \mathrm{~mm})$

At equal distance from a pair of conductors field strength evenly distributed in the water volume and sediment for the measured ranges of $Z$ and was higher in the sediment at the vertical boundaries, even on the layer of compact sandy sediment. Results along the $X$-axis at the vertical boundaries peaked at the centre with $36 \mathrm{~V} \cdot \mathrm{m}^{-1}(\mathrm{X}=162.5)$ and reduced to $23 \mathrm{~V} \cdot \mathrm{m}^{-1}$ towards the conductor $(X=57.5)$ confirming the parabolic shape of the field profile both in the water volume and sediment. When the vertical observed range is narrowed to $+/-100 \mathrm{~mm}$ results of $X=57.5$ and 162.5 compare, showing the electric field is constant in the observed $X$ range over $65 \%$ of the exposed range (325 $\mathrm{mm}$ ) between a conductor pair. After rebuilding the system on the compact sandy sediment results replicated. Along the $X$ axis $(57.5$ and $162.5 \mathrm{~mm}$ ) field strength measured at $100 \mathrm{~mm}$ in the sediment did not reduce at equal distance of the conductors or was higher in compact sandy sediment.

Field strength observed on the $\mathrm{Y}$-axis alongside the conductor did not always peaked opposite the center of the conductor but also at positions aside $(Y=+/-45 \mathrm{~mm})$. These positions changed between levels of $Z$ and varied the most on the layer of mud and sand. This finding differed from the observations in the laboratory where field strength mainly peaked opposite the centre of the conductor $(\mathrm{Y}=0)$. This expresses the contribution of variable conductivity in sediment and water volume. The irregular pattern may add additional electric dynamics to the stimulus, which may have an additional effect on fauna hidden in the sediment.

The background for the low result at $Z=0 / Y=0$ (Figure 21) cannot be explained by this single observation. The dual set-up of two $X$ ranges in a single experiment (Figure 4) or the irregular seabed profile of the Mokbaai seabed might have caused masking.

Results of both sediments for $X=162.5 / Y=+/-45$ (Figure $20 \& 21$ ) support the conclusion that the $Y=0$ artefact is incidental as this was only observed in the $Z=0$ position. Field strength in positions aside the center $(\mathrm{Y}=+/-45)$ were 97 and $95 \mathrm{~V} \cdot \mathrm{m}^{-1}$, while on the compact sandy layer 103 and $98 \mathrm{~V} \cdot \mathrm{m}^{-1}$ was measured. This shows that the contribution of conductivity between both locations (salinity respectively 29 versus 32 ppm, Table 1 ) can be observed in this "balanced" position of X at equal distance from the conductors rather than in close range of a conductor, where the density is irregular and complex. 
The relation with salinity was also observed in the earliest experiments in the tank studies on the UK153 pulse systems of Verburg in 2006 and 2007. A similar contribution of conductivity was observed with peak values measured at $Z=0$ and $X=162.5 \mathrm{~mm}$ proportional to salinity conditions (de Haan, unpublished observation).

The present observations of field strength evenly distributed in the water column and sediment with $31 \mathrm{~V} . \mathrm{m}^{-1}$ at $200 \mathrm{~mm}$ above the seabed. On the earliest experiments on cod in this range (de Haan et al. 2016) a field strength of $40 \mathrm{~V} \cdot \mathrm{m}^{-1}$ referred to the condition which immobilised cod without causing injuries. Given the different conditions (introduction of a sediment layer with lower conductivity, and the offset on the vertical axis $(+22 \mathrm{~mm})$ the present value of $31 \mathrm{~V} \cdot \mathrm{m}^{-1}$ is in range with the laboratory outcome $40 \mathrm{~V} \cdot \mathrm{m}^{-1}$.

The lowest field strength (at $60 \mathrm{~V}$ conductor voltage) presently reported as $22 \mathrm{~V} \cdot \mathrm{m}^{-1}(\mathrm{X}=57.5, \mathrm{Y}=-180$, $Z=0 \mathrm{~mm}$ ) shows that field strength strongly reduced towards the isolator. In the tank study field strength in the position $X=55, Y=-180$ was $23 \mathrm{~V} \cdot \mathrm{m}^{-1}$, although references of $\mathrm{Z}$ differ with $22 \mathrm{~mm}$. Field strength in the closest range as reference to the position where $48 \%$ of the cod became injured (de Haan et al., 2016) was $103 \mathrm{~V} \cdot \mathrm{m}^{-1}(\mathrm{X}=55, \mathrm{Y}=0, \mathrm{Z}=+80)$, while in this research 70-75 V. $\mathrm{m}^{-1}$ was measured at a level at $Z=100 \mathrm{~mm}$. This lower result of $28 \mathrm{~V} \cdot \mathrm{m}^{-1}$ may be explained by the vertical offset of the $Z$ of $42 \mathrm{~mm}$ between both locations.

The only information on field strength responses in sole (Solea solea) are based on a report in preparation showing that when subjected to a pulse frequency range of 16 to $28 \mathrm{~Hz}$ and $50 \mathrm{~V} \cdot \mathrm{m}^{-1}$ all fish immobilised despite their orientation. However, at a field strength of $25 \mathrm{~V} \cdot \mathrm{m}^{-1} 50 \%$ of the tested specimen were immobilised when exposed perpendicular and none in a parallel orientation (Soetaert et al.in prep.). This shows that pulse exposure is likely to produce a response in sole when buried at $100 \mathrm{~mm}$ in the sediment, assuming the observed behaviour also occurs at frequencies > $28 \mathrm{~Hz}$. Depending the orientation of the fish this may also occur up to $200 \mathrm{~mm}$ in the sediment. If true, than the electric stimulus for sole is most efficient at equal distance of the conductors and the stimulus could be more efficient than the conventional tickler chain method, which is likely not to exceed $10 \mathrm{~cm}$ penetration into a sandy stratum. Or when fished on a muddy seabed conventional gear would run aground, while the lighter pulse trawls may have lesser limitations to exploit these fishing grounds.

\section{Validation of the results}

Field strength in closest range of the conductor caused artefacts at highest conductor voltage settings $(60 \mathrm{~V})$. The bipolar signal parts were not always symmetrical and $\delta$ peak varied in the data analysed. To produce one consistent result and to filter out artefacts the data were tested for pulse symmetry. The uncertainty expressed as deviations between bipolar signal parts were in the range of 3 to $6 \%$. Probe positioning errors may have occurred and were out of control in the sediment part. When deviations outranged or occurred on one of the three conductor sets these results were not analysed (Figure 9a \& b). The luxury condition is that field strength was tested for three parallel operated conductors and that data of a single pair of three were excluded, as shown in Table 3 and 4. 


\section{Quality Assurance}

Wageningen Marine Research utilises an ISO 9001:2008 certified quality management system (certificate number: 187378-2015-AQ-NLD-RvA). This certificate is valid until 15 September 2018. The organisation has been certified since 27 February 2001. The certification was issued by DNV Certification B.V.

Furthermore, the chemical laboratory at IJmuiden has NEN-EN-ISO/IEC 17025:2005 accreditation for test laboratories with number L097. This accreditation is valid until $1^{\text {th }}$ of April 2017 and was first issued on 27 March 1997. Accreditation was granted by the Council for Accreditation. The chemical laboratory at IJmuiden has thus demonstrated its ability to provide valid results according a technically competent manner and to work according to the ISO 17025 standard. The scope (L097) of de accredited analytical methods can be found at the website of the Council for Accreditation (www.rva.nl).

On the basis of this accreditation, the quality characteristic $Q$ is awarded to the results of those components which are incorporated in the scope, provided they comply with all quality requirements. The quality characteristic $Q$ is stated in the tables with the results. If, the quality characteristic $Q$ is not mentioned, the reason why is explained.

The quality of the test methods is ensured in various ways. The accuracy of the analysis is regularly assessed by participation in inter-laboratory performance studies including those organized by QUASIMEME. If no inter-laboratory study is available, a second-level control is performed. In addition, a first-level control is performed for each series of measurements.

In addition to the line controls the following general quality controls are carried out:

- Blank research.

- Recovery.

- Internal standard

- Injection standard.

- Sensitivity.

The above controls are described in Wageningen Marine Research working instruction ISW 2.10.2.105. If desired, information regarding the performance characteristics of the analytical methods is available at the chemical laboratory at IJmuiden.

If the quality cannot be guaranteed, appropriate measures are taken. 


\section{References}

Bergman, M.J.N. and Hup, M. 1992. Direct effects of beam trawling on macrofauna in a sandy sediment in the southern North Sea. ICES J. Mar. Sci. 49:5-11.

Bergman, M.J.N. and van Santbrink, J.W. 2000. Mortality in megafaunal bnethic populations caused by trawl fisheries on the Dutch continental shelf in the North Sea in 1994. ICES J. Mar. Sci. 57: 13211331.

Daan, N., 1997. TAC management in North Sea flatfish fisheries. Journal of Sea Research, 37: 321341.

Depestele, J., Ivanović, A., Degrendele, K., Esmaeili, Polet, H., Roche, M., Summerbell, K., Teal, L.R., Venalslander, B., and O'Neill, F. G.. 2016. Measuring and assessing the physical impact of beam trawling. In: Effects of Fishing on Benthic Fauna, Habitat and Ecosystem Function. ICES Journal of Marine Science (2016), 73(Supplement 1), i15-i26. doi:10.1093/icesjms/fsv056.

Eigaard, O.R., Bastardie, Bastardie, F., Breen, M., Dinesen, G.E., Hintzen, N.T., Laffargue, P., Mortensen, L.O., Nielsen, J.R., Nilsson, H.C., O’Neill, F.G., Polet, H., Reid, D.G., Sala, A., Skøld, M., Smith, C., Sørensen, T.K., Tully, O., Zengin, M. Rijnsdorp, A.D. 2016. Estimating seabed pressure from demersal trawls, seines, and dredges based on gear design and dimensions. Contribution to the Supplement: 'Effects of Fishing on Benthic Fauna, Habitat and Ecosystem Function' ICES Journal of Marine Science (2016), 73(Supplement 1), i27-i43. doi:10.1093/icesjms/fsv099.

Fonteyne, R. 2000. Physical impacts of beam trawls on seabed sediments. In: Kaiser, M.J. and de Groot, S.J. (eds). Effects of fishing on Non-Target Species and Habitats. Biological. Conservation and Socio-economic Issues, pp 15-36. Oxford: Blackwell Science.

de Groot, S. J. 1984. The impact of bottom trawling on the benthos fauna of the North Sea. Ocean Management, 9: 177-190.

de Haan, D., Fosseidengen J.E., Fjelldal P.G., Burggraaf D., Rijnsdorp A.D. 2016. Pulse trawl fishing: the effect of electric stimulation on cod. ICES Journal of Marine Science 73: 1557-1569.

Lindeboom, H. J., and de Groot, S. J. 1998. The effects of different types of fisheries on the North Sea and Irish Sea benthic ecosystems. RIVO-DLO Report C003/98. 404 pp.

Rijnsdorp, A. D., Poos, J. J., Quirijns, F. J., HilleRisLambers, R., de Wilde, J. W. and den Heijer, W. M., 2008. The arms race between fishers. Journal of Sea Research, 60: 126-138.

Rijnsdorp, A.D., Bastardie, F., Bolam, S.G., Buhl-Mortensen, L., Eigaard, O.R., Hamon, K.G., Hiddink, J.G., Hintzen, N.T., Ivanović, A., Kenny, A., Laffargue, P., Nielsen, J.R., O’Neill, F.G., Piet, G.J., Polet,H., Sala, A., Smith, C., Denderen, P. D. van, Kooten, T. van, Zengin, M. 2015. Towards a framework for the quantitative assessment of trawling impact on the seabed and benthic ecosystem. ICES Journal of Marine Science; doi:10.1093/icesjms/fsv207.

van Marlen, B., Wiegerinck, J. A. M., van Os-Koomen, E. , van Barneveld, E. 2014. Catch comparison of pulse trawls and a tickler chain beam trawl. Fisheries Research, 151: 57-69.

Soelaert, M., de Haan, D., Verschueren, B., Decostere, A., Chiers, K. 2016. Atlantic Cod Show a Highly Variable Sensitivity to Electric-Induced Spinal Injuries. Marine and Coastal Fisheries Dynamics Management and Ecosystem Science 8(1):412-424. DOI: 10.1080/19425120.2016.1180332.

Soelaert, M., Sys, K., Lenoir, H. 2018. (in prep.).Reducing bycatch in beam trawls without loss of commercial sole by using a $200 \mathrm{~mm}$ square mesh electrified benthos release panel. ICES Journal of Marine Science. 


\section{Justification}

Report C022/18

Project Number: 4318200013

The scientific quality of this report has been peer reviewed by a colleague scientist and a member of the Management Team of Wageningen Marine Research

Approved: $\quad$ dr. A.D. Rijnsdorp

senior scientist

Signature:

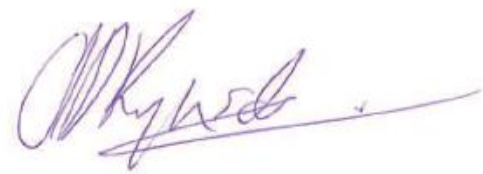

Date:

12-09-2018

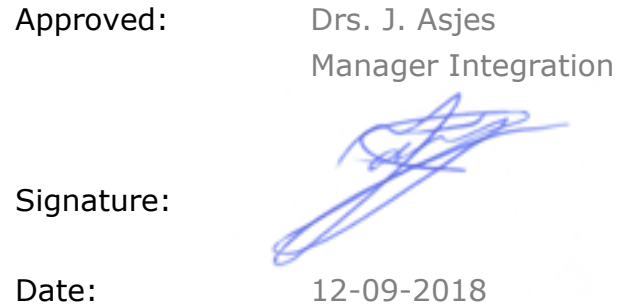


Wageningen Marine Research

T +31(0)317480900

E: marine-research@wur.nl

www.wur.eu/marine-research

Visitors' address

- Ankerpark 271781 AG Den Helder

- Korringaweg 7, 4401 NT Yerseke

- Haringkade 1, 1976 CP IJmuiden
Wageningen Marine Research is the Netherlands research institute established to provide the scientific support that is essential for developing policies and innovation in respect of the marine environment, fishery activities, aquaculture and the maritime sector.

\section{Wageningen University \& Research:}

is specialised in the domain of healthy food and living environment.

\section{The Wageningen Marine Research vision}

'To explore the potential of marine nature to improve the quality of life'

\section{The Wageningen Marine Research mission}

- To conduct research with the aim of acquiring knowledge and offering advice on the sustainable management and use of marine and coastal areas.

- Wageningen Marine Research is an independent, leading scientific research institute

Wageningen Marine Research is part of the international knowledge organisation Wageningen UR (University \& Research centre). Within Wageningen UR, nine specialised research institutes of the Stichting Wageningen Research Foundation have joined forces with Wageningen University to help answer the most important questions in the domain of healthy food and living environment. 